Rhode Island College

Digital Commons @ RIC

Master's Theses, Dissertations, Graduate

Master's Theses, Dissertations, Graduate Research and Major Papers Overview

Research and Major Papers

8-9-2020

\title{
An IV Anesthetic Decision Tree for Cardiac Surgery
}

Brian Doucette

Follow this and additional works at: https://digitalcommons.ric.edu/etd

\section{Recommended Citation}

Doucette, Brian, "An IV Anesthetic Decision Tree for Cardiac Surgery" (2020). Master's Theses, Dissertations, Graduate Research and Major Papers Overview. 350.

https://digitalcommons.ric.edu/etd/350

This Major Paper is brought to you for free and open access by the Master's Theses, Dissertations, Graduate Research and Major Papers at Digital Commons @ RIC. It has been accepted for inclusion in Master's Theses, Dissertations, Graduate Research and Major Papers Overview by an authorized administrator of Digital Commons @ RIC. For more information, please contact digitalcommons@ric.edu. 


\section{CREATION OF A PRELIMINARY EVIDENCE-BASED DECISION TREE FOR SELECTING AN INTRAVENOUS ANESTHETIC FOR CARDIAC SURGERY}

by

Brian R. Doucette

A Major Paper Submitted in Partial Fulfillment

of the Requirements for the Degree of

Master of Science in Nursing

in

The School of Nursing

Rhode Island College

2020 


\begin{abstract}
Induction of anesthesia is often associated with hemodynamic instability. Patients undergoing cardiac surgical procedures are at a heightened risk of morbidity and mortality due to weakened heart function and thus hemodynamic stability is of paramount importance. Anesthesia providers often base clinical decisions on personal preference rather than evidence-based factors. Decision trees can provide a reference tool to guide evidence-based decision-making. The purpose of this paper was to propose a preliminary, evidence-based decision tree to guide in the selection of an appropriate intravenous anesthetic for patients undergoing cardiac surgery. Information Processing Theory and PRISMA were used as frameworks to guide the research process and creation of the decision tree. Nine randomized controlled trials published in the last ten years were identified and relevant data were extracted and organized into data tables. Quality of the studies were evaluated utilizing the CASP method and PRISMA. A cross-study analysis was performed to identify common findings across studies. Recommendations for appropriate interventions at decision points were developed from the cross-study analysis. Advanced Practice Registered Nurses are uniquely qualified to integrate evidence-based decision-making tools into everyday clinical practice. Nursing education and nursing practice emphasize using the most current evidence to guide patient care. Certified Registered Nurse Anesthetists are looked upon to demonstrate leadership within their organizational structures to identify areas for improvement, seek out evidence to guide change, and implement that change within their sphere of influence and beyond.
\end{abstract}




\section{Acknowledgements}

First and foremost, I would like to thank my wife Rebecca. My success in this program is a direct result of the love and support you have shown me throughout this process. You kept my priorities focused and our family afloat. I am eternally grateful. My children have been a constant motivator and keep me grounded. Henry, Benjamin and Elise, I hope someday you will understand that my absence during this time was ultimately for the purpose of providing you a better future. Thank you to Dr. Cynthia Padula, who guided me through this project. Thank you to our program directors and faculty for your lessons and mentorship. Thank you to Katie Ricci, CRNA, who served as my third reader. You have been a good friend for many years. Last, but certainly not least, thank you to my classmates. When we embarked on this journey, I don't think we had any idea what it would be like. If we told anyone what it was actually like, they wouldn't believe us. I feel incredibly fortunate to have experienced all of the ups and downs alongside all of you. 


\section{Table of Contents}

Background/Statement of the Problem .................................................................. 1

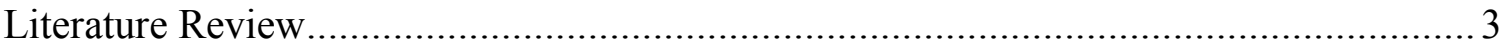

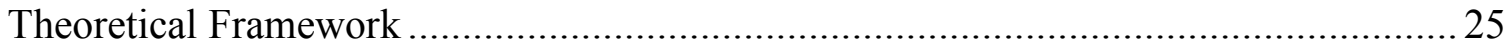

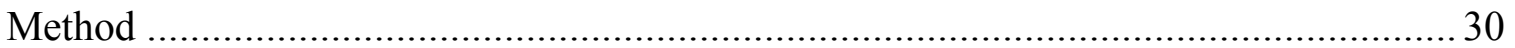

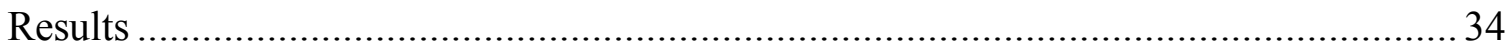

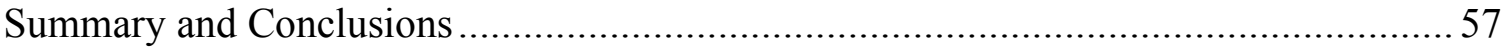

Recommendations and Implications for Advanced Nursing Practice ........................... 61

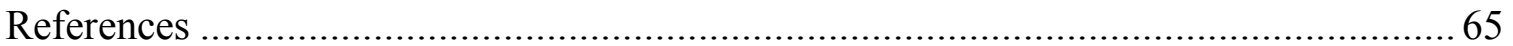

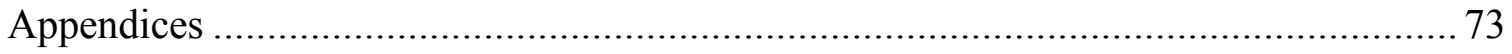


Creation of a Preliminary Evidence-Based Decision Tree for Selecting an Intravenous Anesthetic for Cardiac Surgery

\section{Background/Statement of the Problem}

During induction of anesthesia, a patient is taken from the pre-procedure state of consciousness to a state characterized by lack of consciousness, awareness, and reflexes. During this process, patients lose nearly all physiologic self-protection mechanisms. It's incumbent upon anesthesia providers to utilize the best options available to execute an induction with the least chance of negative effects for the patient. While multiple options are available to facilitate induction, the use of intravenous anesthetic medications is the most typical technique used with adult patients (Dean \& Chapman, 2018). Despite the risks involved and availability of information, anesthesia providers often select particular medications based on factors unrelated to individualized patient needs or best practices (Munst, Schlapfer, \& Biro, 2018).

Propofol, etomidate, and ketamine are the most commonly used intravenous anesthetics in the United States today. Each of these medications possesses distinct mechanisms of action, durations of action, side effects, and risks associated with their use. This information is a component of basic education in anesthetic pharmacology. Clinical training reinforces classroom work by providing opportunities during which student anesthesia providers witness the effects and patient responses to these medications and respond accordingly under the supervision of more experienced colleagues. Patients undergoing cardiac surgery are at much greater risk for complications due to underlying cardiac disease and lack of physiologic reserve (Contrera, Patterson, \& Cushing, 2014). It's imperative that the anesthesia provider ensure a safe induction for patients and specifically for those undergoing cardiac surgery. 
Each anesthetic involves numerous instances where the anesthesia provider must choose a suitable intervention in response to an occurrence. Despite years of training and common basic understanding, large variations in practice and decision-making continue to cause delays and errors in treatment, many of which result in patient harm (Stiegler \& Tung, 2014). Decision-making aids, clinical pathways, and algorithms have been developed in most healthcare disciplines to provide practitioners with evidence-based tools to assist in selecting the most appropriate intervention in a given situation. Properly tailored, created, and implemented, these tools have been shown to significantly reduce morbidity and mortality (Rotter et al., 2012).

The purpose of this paper was to propose a preliminary, evidence-based decision tree to guide in the selection of an appropriate intravenous anesthetic for patients undergoing cardiac surgery.

Next, the review of the literature will be presented. 


\section{Literature Review}

A literature review was performed utilizing the research databases Academic Search Complete, CINAHL Plus with Full Text, and MEDLINE. Search terms included induction of anesthesia, intravenous induction agents, propofol, etomidate, ketamine, cardiac surgery, coronary artery bypass graft, valvular disease, decision making, and decision tree, which were searched individually and in combination. The search was limited to articles published in the last ten years. Reference sections of located articles were also mined for additional applicable articles.

\section{Induction of Anesthesia}

General anesthesia is a state in which a patient is pharmacologically rendered completely unconscious and unresponsive to all external stimuli (American Society of Anesthesiologists [ASA], 2014). Under general anesthesia, patients are unable to independently support their own airway patency and ventilatory status and often require assistance to preserve cardiac and vascular function. The induction phase is the portion of the anesthesia process during which the patient is taken from his/her pre-anesthetic state to a state of general anesthesia (Nagelhout, 2014). Induction of general anesthesia is carried out with the administration of either inhalation anesthetics or intravenous anesthetics.

Inhalation Induction. The first use of inhalation anesthetics can be traced to the mid-1800s, during which the use of ether, chloroform, and nitrous oxide became common methods used to induce and maintain general anesthesia (Khan, Hayes, \& Buggy, 2014a). The effects of inhalational anesthetics were once thought to be directly related to their chemical property of solubility in lipids, with those agents expressing a greater degree of lipid solubility exhibiting greater potency. Further research has discovered that the 
effects of inhalational anesthetics are far more nuanced, with differing mechanisms in the spinal cord, above the spinal cord in the brain, at ion channels and nerve synapses, and upon particular protein subunits at the molecular level. Movement into, through, and out of the body is primarily related to the lipid solubility of the inhalation anesthetic, but also affected by the particular patient's cardiovascular status, ventilatory function, and amount of adipose tissue (Khan et al.).

Inhalational anesthetics are not without their risks and side effects. For example, two of the commonly available agents, isoflurane and desflurane, are quite pungent and cause airway irritation and coughing, which is troublesome for patients with reactive airway disease (Kossick, 2014). Inhalation anesthetics cause systemic vasodilation leading to decreases in mean arterial pressure (MAP) and cardiac output (CO) and can generate arrhythmias. All of the volatile inhalation anesthetics are potent triggers of malignant hyperthermia, which is an anesthetic emergency and can lead to fatal elevations in body temperature (Kossick).

Inhalation induction is accomplished with the exclusive administration of one of the volatile anesthetic gases (Dean \& Chapman, 2018). A mask is placed over the face and the patient inhales larger concentrations of an inhalation anesthetic than would be normally used for the maintenance phase. Inhalation induction is commonly employed with pediatric patients, who are more likely to express fear of needles. Inhalation anesthetics result in a longer induction time and increase the risk of laryngospasm. With the exception of children and those patients with severe aversion to needles, inhalation induction has been replaced with intravenous induction in the overwhelming majority of cases (Dean \& Chapman). 
Intravenous Induction. Similar to inhalation induction, intravenous induction is the process by which patients are transitioned to a state of general anesthesia utilizing medications that are administered intravenously rather than into the lungs. Intravenous induction produces a faster transition from consciousness to general anesthesia than the inhalational method (Nagelhout, 2014). Intravenous induction also produces a smoother process, which is generally more enjoyable for the patient. Intravenous anesthetics are not known to generate laryngospasm and produce a rapid, controlled induction process that can be tailored to the specific physiologic demands of each individual (Nagelhout). Rapid sequence induction (RSI) is a modified form of intravenous induction whereby an intravenous anesthetic is administered, immediately followed by a neuromuscular blocking agent to render the patient immediately unconscious and immobile to facilitate airway management in patients at greater risk of aspirating stomach contents (Dean \& Chapman, 2018).

\section{Intravenous Anesthetics}

Thiopental entered common use in the early 1930 s and is generally considered the first intravenous anesthetic (Khan, Hayes, \& Buggy, 2014b). A myriad of intravenous anesthetics have been developed since, although only four agents, propofol, etomidate, ketamine, and thiopentone, are in general use (Dean \& Chapman, 2018). Thiopentone was removed from the United States market in 2011, leaving propofol, etomidate and ketamine as the intravenous anesthetics most commonly used today (Nagelhout, 2014).

Propofol. First patented in 1977 by Roger James and John Glen, propofol was introduced in the United States as an intravenous anesthetic in 1989 (Sahinovic, Struys, \& Absalom, 2018). It is only soluble in lipid-based emulsions and is formulated to 
include glycerol, soybean oil, and egg lecithin (Sahinovic et al). Despite this formulation, propofol has been shown to be safe for use in patients with known allergies to eggs and soy (Harper, 2016). Initially, propofol was found to have a propensity for harboring bacteria and easily becoming contaminated (Sahinovic et al.). This problem was rectified by the addition of ethylenediaminetetracetic acid (EDTA), which was added as a preservative to decrease the incidence of contamination (Sahinovic et al.). Many generic forms of propofol, especially those manufactured outside the United States, utilize other preservatives including sodium metabisulfite (Nagelhout, 2014). This is problematic for patients with known sulfite allergies. Name brand propofol, marketed as Diprivan (C) in the United States, is only available with the EDTA preservative (Nagelhout). Facilities that use generic formulations should keep a small cache of EDTA-preserved propofol on hand for use in patients with sulfite allergies. Notwithstanding the presence of the preservative, it is generally accepted practice to discard any propofol that was removed from its original vial within six hours of doing so and to discard any container that has been accessed within 12 hours of opening (Nagelhout).

Pharmacologically, propofol is characterized by a rapid onset due to its high lipid solubility (Sahinovic et al., 2018). The speed with which molecules cross lipid membranes is directly related to the lipid solubility characteristics of the molecule. As such, propofol easily crosses the blood-brain barrier (BBB), rapidly inducing a state of general anesthesia. Lipid soluble molecules can cross lipid membranes in both directions. Rapid redistribution of propofol from the brain back into the bloodstream accounts for the relatively fast wake-up time after a bolus dose. Once back in the blood- 
stream, propofol molecules will deposit into other areas where lipid membranes exist, such as adipose tissue (Sahinovic et al.). Although the therapeutic effects of propofol will not generally be observed after redistribution, the body must still metabolize it before it is eliminated from the body. The speed with which this occurs is dependent upon the blood supply to the areas in which the molecules were deposited. If propofol is administered as an infusion, the duration of the infusion will determine the extent to which molecules are deposited in other areas of the body. Termed the context-sensitive half time, the duration of time necessary for the plasma concentration of propofol to be reduced by $50 \%$ after stopping the infusion will be longer for infusions of greater duration and in patients with a large amount of adipose tissue (Sahinovic et al.).

Propofol acts upon the $\gamma$-amino butyric acid receptor $\left(\mathrm{GABA}_{\mathrm{A}}\right)$ in the central nervous system (CNS) (Nagelhout, 2014). The ligand for that receptor, $\gamma$-amino butyric acid (GABA), is one of the most important neurotransmitters in the CNS for inhibiting neuronal activity. Upon binding of GABA to $\mathrm{GABA}_{\mathrm{A}}$, ligand-gated chloride channels open and facilitate the movement of ions, altering membrane potential. The altered membrane potential inhibits depolarization of the neuron, decreasing its activity. Propofol does not directly bind to $\mathrm{GABA}_{\mathrm{A}}$. It stimulates the receptor to bind to the patient's own GABA and elicit the response (Nagelhout).

Upon administration and onset of a dose of propofol, a number of normal physiologic mechanisms are depressed (Khan et al., 2014b). Administration is followed by rapid loss of consciousness. Propofol constricts cerebral blood vessels, leading to a decrease in cerebral blood flow (Nagelhout, 2014). This decrease contributes to a lowering of intracranial pressure. Depression of neuronal activity reduces the cerebral 
metabolic rate of oxygen consumption $\left(\mathrm{CMRO}_{2}\right)$ (Nagelhout). Neuronal depression additionally contributes to propofol's ability to act as an anticonvulsant and antiemetic (Sahinovic et al., 2018). Propofol also exhibits substantial cardiorespiratory changes. It is a direct suppressant of myocardial activity and vascular tone. As a result, myocardial inotropy, arterial vasoconstriction and venous return are all reduced. Profound hypotension and reflex tachycardia can occur. In induction doses, propofol produces apnea, loss of gag reflex, and loss of muscle control of the larynx, which are helpful during airway management (Sahinovic et al.). Direct intravenous injection of propofol can cause irritation of the local blood vessel and pain with injection (Nagelhout, 2014).

Awakening after a dose of propofol is based upon the medication leaving the CNS and is virtually unaffected by metabolism of the drug (Nagelhout, 2014). The liver quickly performs phase I metabolism via the cytochrome P450 system, with metabolites being conjugated during phase II metabolism by glucuronic acid; the metabolites are pharmacologically inactive (Sahinovic et al., 2018). The demonstrated rate of metabolism is in excess of hepatic blood flow. Propofol metabolism has also been demonstrated in the kidneys, small intestines, and lungs. Greater than $99 \%$ of a dose of propofol is excreted after metabolism, with a fractional amount excreted in its native chemical structure. The vast majority of the metabolites are excreted by the renal system, although small amounts are excreted through the lungs upon exhalation. In some patients, after prolonged exposure to propofol infusions, some of the metabolites can discolor the patient's urine bluish-green (Sahinovic et al.).

Etomidate. Etomidate was initially created in the mid 1960's and became commonplace in clinical practice in the early 1970's (Nagelhout, 2014). It was originally 
utilized for treating fungal infections prior to the discovery of its anesthetic capabilities (Forman, 2011). Etomidate's chemical structure expresses chirality, with two possible enantiomers. Refined preparations of the $\mathrm{R}(+)$-enantiomer have been shown to be significantly safer than a racemic mixture. Commercially available etomidate is supplied as the pure $\mathrm{R}(+)$-enantiomer (Forman).

Etomidate's effects are mediated by the $\mathrm{GABA}_{\mathrm{A}}$ receptor (Forman, 2011). Etomidate increases GABA's affinity for $\mathrm{GABA}_{\mathrm{A}}$ by binding to a specific location within the $\mathrm{GABA}_{\mathrm{A}}$ receptor (Rathmell \& Rosow, 2015). Etomidate's pharmacokinetic profile is similar to propofol. Rapid unconsciousness is realized due to etomidate's high lipid solubility and propensity for crossing the BBB (Nagelhout, 2014). Its action upon $\mathrm{GABA}_{\mathrm{A}}$ receptors stimulates the opening of ligand-gated ion channels, inhibiting neuronal activity. Short duration of action is related to redistribution out of the CNS. Metabolism occurs via the cytochrome P450 system to water soluble substances (Nagelhout). All but a small fraction of the metabolites, which have no pharmacologic function, are excreted in the urine, with the remainder removed from the body through the GI tract as a component of bile (Rathmell \& Rosow, 2015).

Etomidate produces a rather unique pharmacodynamic response. Etomidate causes a constriction of cerebral blood vessels, which produces a reduction in $\mathrm{CMRO}_{2}$ and intracranial pressure (ICP) (Nagelhout, 2014). Cerebral perfusion pressure is maintained. When administered as a component of the anesthesia regimen for electroconvulsive therapy (ECT), etomidate prolongs the neurologic seizure activity seen on electroencephalogram (EEG) (Nagelhout). Routine administration to patients with a known history of epilepsy should be avoided (Rathmell \& Rosow, 2015). Although 
etomidate has shown to prolong seizure activity during ECT, it has also been shown to provide some action as an anticonvulsant and has been used successfully during the treatment of status epilepticus. Etomidate is known for its stable cardiovascular response. Stroke volume (SV), heart rate (HR), and cardiac output (CO) are maintained, while a slight decrease in systemic vascular resistance (SVR) may occur. Etomidate's stable cardiovascular profile has led to its common use in patients with depressed heart function, severe trauma, and other clinical situations involving hemodynamically compromised patients. Etomidate has been demonstrated to depress myocardial contractility; however, quantities needed to elicit this response far exceed the therapeutic dose (Rathmell \& Rosow). The baroreceptor reflex and sympathetic tone are maintained (Nagelhout, 2014). Arrhythmias of any clinical significance are rare. Patients carrying diagnoses of mitral or aortic valve pathologies may experience acute hypotension after receiving Etomidate. With the exception of a possible transitory period of apnea after the administration of an induction dose, respiratory rate is maintained. Histamine is not released in response to administration and there is no effect on bronchial smooth muscle (Nagelhout).

Etomidate produces some adverse effects that must be weighed against its benefits and may limit use in certain patients. The most significant adverse effect of etomidate is its inhibition of steroid synthesis by the adrenal glands (Erdoes, Basciani, \& Eberle, 2014). Etomidate is a potent inhibitor of $11 \beta$-hydroxylase, a microsomal enzyme of the cytochrome $\mathrm{P} 450$ system, which is responsible for a critical step in the cascade of reactions that produces cortisol. Adrenal inhibition is greater than the anesthetic effect for a given dose and can continue for 24-72 hours in some patients. This has resulted in 
the discontinuation of etomidate for long-term intravenous infusions in critically ill patients (Erdoes et al.). Mixed results from several randomized studies have created controversy about its use in bolus doses in patients for whom a depressed adrenal stress response could prove detrimental (Nagelhout, 2014). Studies examining the efficacy of supplementing affected patients with exogenous steroids have also demonstrated mixed results (Nagelhout). Etomidate also causes myoclonus, which is an episode of involuntary muscle contractions sometimes misinterpreted as seizure activity. This is thought to be a result of disparate timing of action in certain parts of the brain, during which inhibitory neurons are anesthetized prior to excitatory neurons, resulting in overexcitation of the excitatory pathways (Nagelhout). This usually has little clinical significance, as etomidate is routinely accompanied by medications that produce neuromuscular blockade and skeletal paralysis. Patients experience pain at the site of injection and etomidate has been directly linked to post-operative nausea and vomiting (PONV) (Forman, 2011).

Another important physiologic effect that must be considered is the relationship of etomidate to the condition porphyria. Porphyrias are genetically inherited or acquired metabolic disorders resulting in a decreased supply of an enzyme required to synthesize heme, a foundational component of the hemoglobin molecule (Nagelhout, 2014). Porphyrins are chemical precursors to heme, which can cause neurologic damage if they accumulate in high doses. Etomidate is an inducer of the enzyme ALA-synthetase, the enzyme that catalyzes as the rate-limiting step in the cascade of reactions that produce heme. Induction of ALA-synthetase increases the rate of production of porphyrins. The patient with a porphyria cannot maintain a heme production rate equivalent to the rate of 
porphyrin production, causing them to accumulate. Etomidate is contraindicated in patients with a recognized porphyria (Nagelhout).

Ketamine. Various sources report the first use of ketamine in the clinical setting sometime in the mid-1960s to early 1970s (Khan et al., 2014b; Nagelhout, 2014). Ketamine is a hydrophilic molecule that contains a single chiral carbon, with two possible enantiomers (Rathmell \& Rosow, 2015). The racemic mixture of both enantiomers is the primary formulation that is commercially available. A pure formulation of the $\mathrm{S}(+)$ enantiomer exists but is not in common use. $\mathrm{S}(+)$-ketamine was found to offer superior desired effects with fewer untoward reactions (Rathmell \& Rosow). S(+)-ketamine has been found to offer only trivial clinical benefits that don't justify the costs associated with isolating the pure preparation (Nagelhout, 2014).

Ketamine's mechanism of action is substantially dissimilar to that of propofol or etomidate (Nagelhout, 2014). The primary site of action is at the N-methyl-D-aspartate (NMDA) receptor, although it has been shown to display effects at other receptors as well, including adenosine, cholinergic, monoamine, opioid, and purinergic receptors. Ketamine also alters gene expression of interleukin-6 (IL-6) and tumor necrosis factoralpha (TNF- $\alpha$ ), providing some anti-inflammatory effects. Ketamine can also be used for its direct analgesic properties, whereby it blocks the transmission of pain in the dorsal horn of the spinal cord (Nagelhout). Ketamine's actions at the GABA receptor is negligible (Rathmell \& Rosow, 2015). One of Ketamine's main benefits is its compatibility with multiple routes of administration in addition to the intravenous route. It can be administered via the intraosseous, intramuscular, intranasal, and oral routes; a Ketamine lozenge is also available (Marland et al., 2013). 
Ketamine's high lipid solubility leads to it easily crossing the BBB, leading to rapid unconsciousness, followed by redistribution out of the CNS leading to a short duration of action (Rathmell \& Rosow, 2015). Metabolism is carried out by the cytochrome P450 system in the liver. The principal metabolite of ketamine is norketamine, which has active pharmacologic effects, prolonging the effects at receptors outside the CNS. Phase II metabolism conjugates norketamine into an inactive hydrophilic compound, promoting renal elimination. Ketamine serves to induce the cytochrome p450 enzymes responsible for its metabolism, accelerating its elimination half-life over time. Tolerance can develop with prolonged use (Rathmell \& Rosow).

Ketamine produces a wide array of pharmacodynamic effects. Intravenous administration of an induction dose creates a state of dissociative anesthesia, whereby the patient enters a catatonic state (Nagelhout, 2014). The patient does not interact with the environment but may appear awake. Central nervous system reflexes, including corneal and pupillary reflexes, are maintained. A cardinal sign of Ketamine administration is nystagmus. Patients can sneeze, cough, and swallow, while maintaining airway protective reflexes. Ketamine administration is accompanied by increased oral secretions, which increases the possibility of laryngospasm in the setting of preserved airway reflexes. Ketamine dilates cerebral blood vessels, leading to an increase in cerebral blood flow (CBF), $\mathrm{CMRO}_{2}$ and ICP. Ketamine is generally avoided in patients at risk for increased ICP (Nagelhout).

Ketamine's desirability in critically ill patients is related to its cardiovascular effects. Ketamine causes sympathetic stimulation of the myocardium, resulting in increases in HR, CO, and SVR (Rathmell \& Rosow, 2015). Myocardial workload 
intensifies, which increases myocardial oxygen demand. Blood pressure (BP) in the pulmonary circuit and system circuit are augmented. Serum lactate levels may increase (Rathmell \& Rosow). A different medication should be chosen for patients who struggle to control their BP, or for those with a known history of ischemic heart disease (Khan et al., 2014b). Ketamine is not a catecholamine, so does not directly stimulate adrenergic receptors in the heart or blood vessels (Rathmell \& Rosow, 2015). Ketamine's sympathomimetic effects are likely derived from the stimulation of endogenous catecholamines or interfering with their reuptake. Patients suffering from catecholamine depletion have demonstrated cardiac depression after receiving ketamine. Respiratory depression is insignificant, other than transient apnea following swift administration of an induction dose. Ketamine causes bronchodilation and is considered the most desirable IV induction agent for patients experiencing symptomatic reactive airway disease (Rathmell \& Rosow). Several international organizations have published recommendations that include ketamine as the first or only choice of IV anesthetic in emergency situations, trauma, and in developing countries (Morris, Perris, Klein, \& Mahoney, 2009).

Adverse reactions limit the use of ketamine in certain situations. Emergence delirium, with concomitant auditory and visual hallucinations, temporary blindness and vivid dreams, commonly occurs (Rathmell \& Rosow, 2015). Acute schizophrenia and other psychotic symptoms have been reported (Marland et al., 2013). Ketamine has been shown to lower the incidence cognitive dysfunction in patients undergoing cardiothoracic surgical procedures (Hudetz et al., 2009). The safety of ketamine in patients with porphyrias is controversial; use should be reserved for situations in which the benefits far outweigh the risks (James \& Hift, 2000). 


\section{Anesthesia Induction for Cardiac Surgery}

Cardiac surgery can present a challenging set of circumstances for the anesthesia provider. Patients often come to surgery with a myriad of coexisting diseases, while cardiovascular status has deteriorated to the point that surgical correction is required. Tight control of hemodynamic stability is essential while accounting for existing comorbidities and pharmacologic side effects (Mittnacht, London, Puskas, \& Kaplan, 2018). Selection of the appropriate IV anesthetic will be guided by the pathophysiology of the particular cardiac condition for which the patient requires repair.

Valvular Disease. Blood travels through a valve as it exits each chamber of the heart. Properly functioning, valves prevent retrograde blood flow while permitting unimpeded antegrade flow, generating a predictable pressure/volume relationship in each chamber (Contrera et al., 2014). While disease in the valves of the left heart are common, valve disease in the right heart is considerably less likely (Contrera et al.). Cardiovascular sequelae from valve disease can include structural changes such as hypertrophy, arrhythmias, and frank cardiac failure (Herrera, 2018). Diseased valves can either fail close properly (regurgitation) or fail to open completely (stenosis). The structural changes and symptomatology differ according to valve and pathology. Anesthesia providers must choose the appropriate medications based upon the particular valve involved, the type and severity of the valve condition, and the cardiovascular pharmacodynamics of the particular drug (Herrera).

Aortic Stenosis. The most commonly occurring valve disease in the industrialized world, aortic stenosis is a condition in which the aortic valve is unable to open completely (Contrera et al., 2014). While usually a result of calcification of the 
valve, a small segment of the population is born with a bicuspid valve (a normal valve has three cusps), which is more likely to stenose (Herrera, 2018). Patients with a bicuspid valve develop symptoms earlier in life and often require surgical correction at a younger age (Herrera).

In response to the decreased movement of blood into the systemic circulation, the heart compensates by generating more pressure in the left ventricle to maintain cardiac output (Herrera, 2018). The structural response is consistent with increased workload by any muscle group, in that it stiffens and hypertrophies. The hypertrophied left ventricle balances the strength of contraction with the degree of stenosis to maintain a pressure gradient on either side of the valve. The additional workload on the heart muscle substantially increases oxygen demand (Herrera). The hypertrophied ventricle cannot relax appropriately, leading to diastolic heart failure (Paul \& Des, 2017).

Anesthetic management of aortic stenosis involves maintaining the pressure gradient between the left ventricle and the aorta (Contrera et al., 2014). Emphasis must be placed on preserving adequate preload, maintenance of synchrony between the atria and ventricles, assuring sufficient time for ventricular filling, and preventing abrupt reductions in systemic blood pressure. Volume replacement may be necessary to provide enough preload to expand the stiffened ventricle. Tachycardia decreases the time spent in the diastolic phase of the cardiac cycle, leading to insufficient ventricular filling time. Conversely, bradycardia drops overall cardiac output, which may not meet the demands of systemic circulation (Contrera et al., 2014). The atria provide nearly half of the overall cardiac output in the setting of aortic stenosis (Paul \& Des, 2017). Loss of atrioventricular synchrony, as can occur with atrial fibrillation, will cause significant 
declines in left ventricular ejection. Systemic hypotension must not be permitted to occur and afterload must be maintained. A decrease in the pressure gradient across the stenotic valve will interfere with diastolic coronary artery filling and ischemia will result (Paul \& Des). The best choice of induction agent will maintain SVR while preserving cardiac function and preventing arrhythmias or large changes in heart rate (Herrera, 2018).

Aortic Regurgitation. Failure of the aortic valve to completely close during diastole permits blood to regurgitate into the left ventricle (Contrera et al., 2014). The consequences are twofold. First, systemic cardiac output is decreased, as a portion of the blood that was ejected returns to the left ventricle through the incompetent valve. Second, increased diastolic volume, (regurgitant flow plus atrial flow) causes the ventricle to enlarge to accommodate it (Contrera et al.). The ventricle will hypertrophy and increase wall tension over time to generate the pressures needed to eject the increased volume in sufficient quantity to maintain cardiac output (Paul \& Des, 2017). Prolonged, untreated aortic regurgitation can exceed the ability of the heart to compensate, resulting in systolic heart failure (Paul \& Des). The best induction agent will maintain or slightly increased HR while lowering SVR (Herrera, 2018). Higher heart rates decrease ventricular filling time, preventing an excessive dilation of the chamber. Decreased afterload lowers the pressure against which the heart must pump to maintain cardiac output, decreasing workload.

Mitral Stenosis. Mitral stenosis is the result of a failure of the mitral valve to open completely during diastole (Contrera et al., 2014). It is not very common in the industrialized world and is overwhelmingly associated with rheumatic heart disease. 
Pressure increases in the left atrium causing dilation and backward pressure into the pulmonary circulation. Similar to mitral regurgitation, atrial fibrillation, pulmonary hypertension, and right heart failure can occur. The chief insult to cardiac function with mitral stenosis is a deficit in left ventricular filling through the narrowed valve opening (Contrera et al.). Systemic vascular resistance should have little effect on overall cardiac function, as mitral stenosis has little effect on left ventricular function (Herrera, 2018). Choice of IV anesthetic should be directed at maintaining or decreasing heart rate to prolong diastolic filling time and augment left ventricular preload (Herrera).

Mitral Regurgitation. Mitral regurgitation is a result of backward flow of blood through an incompletely closed valve (Contrera et al., 2014). The mitral valve is normally closed during the systolic phase of the cardiac cycle. Mitral regurgitation permits backward flow of blood into the left atrium when the left ventricle contracts. Backflow into the atria, coupled with forward flow from the pulmonary circulation, causes increases in volume and pressure in the left atrium. Dilation of the left atrium interferes with conduction of action potentials. As a result, mitral regurgitation is often accompanied by atrial fibrillation (Contrera et al.). Continuous blood supply from the right heart and regurgitation into the left atrium will ultimately lead to increased left heart and ultimately left ventricular volume (Paul \& Des, 2017). Left untreated, chronic mitral regurgitation will lead to systolic heart failure; this will extend the increased backpressure through the left atrium, into the pulmonary circulation, and into the right heart, leading to right heart failure (Paul \& Des). Choice of IV anesthetic is guided by similar factors as with aortic regurgitation (Herrera, 2018). Decreasing SVR will lessen the pressure against which the heart must pump to maintain cardiac output. Maintaining or slightly 
increasing heart rate will shorten the duration of ventricular filling, minimizing excessive left ventricular pressure, and therefore decreasing the degree of retrograde flow (Herrera).

Coronary Artery Disease. Coronary artery disease (CAD) takes a significant toll on the health of Americans. It is one of the leading causes of death in the United States, and the incidence of CAD is increasing (Mittnacht et al., 2018). Hundreds of thousands of people undergo coronary artery bypass grafting $(\mathrm{CABG})$ procedures annually. Coronary artery disease is the end-result of numerous physiologic processes that contribute to the narrowing of the lumen of the arteries that provide oxygenated blood to heart muscle cells (Contrera et al., 2014). Decreased lumen size leads to decreased oxygen supply. Oxygen consumption is determined by combined effects of the rate at which the heart beats, the strength of contraction, and the stress exerted against the walls of the heart chambers by internal pressure (Hibbert, Nathan, Simard, \& O'Brien, 2018). If oxygen demand exceeds supply, patients can experience symptoms including chest pain and dyspnea (Contrera et al., 2014). Patients with long-standing ischemic heart disease may also possess comorbid systolic heart failure and reduced ejection fraction. These patients have even less cardiac reserve and may lack the ability to compensate for even the slightest insult to their hemodynamics (Contrera et al.).

While there are many considerations to be made throughout the course of an anesthetic for $\mathrm{CABG}$, preventing ischemia remains the primary concern during the induction phase. Ischemia prevention is accomplished by preservation of the patient's myocardial oxygen supply versus demand, ensuring that demand doesn't exceed supply (Mittnacht et al., 2018). Selection of an IV anesthetic for CABG should focus on maintenance or optimization of the patient's pre-operative hemodynamic status (Contrera 
et al., 2014). Tachycardia will increase myocardial oxygen demand. Bradycardia may prevent the heart from producing sufficient cardiac output and coronary artery perfusion may suffer. Sustaining the BP as close to baseline as possible is optimal. Hypertension increases the amount of work the heart must do to overcome afterload and sustain cardiac output. Hypotension is least desirable, resulting in decreased coronary perfusion and oxygen supply. Increased inotropy will increase oxygen demand, while decreasing contractility, if tolerated, will reduce it. The best IV anesthetic for CABG will be the choice that achieves a smooth induction while preventing tachycardia and maintaining a stable BP commensurate with the patient's baseline (Contrera et al.).

\section{Decision-Making in Anesthesia}

Substantial incongruence exists in healthcare decisions made by different practitioners pertaining to the same question (Cozmuta, Merkel, Wahl, \& Fraenkel, 2014). Often, subject matter experts cannot agree on the proper treatment course. The outcomes of these decisions can have significant consequences depending on the situation and any confounding factors involved (Cozmuta et al.). Medical error is commonplace, often with grave consequences (Stiegler \& Tung, 2014). Errors frequently lead to delays in care, especially in high pressure environments. When errors occur, they may be accompanied by greater magnitudes of morbidity or mortality and can lead to litigation. Real-world investigations and simulated patient scenarios have demonstrated large variations and inconsistencies in decision-making, as well as failure to adhere to accepted practice, and in some instances, treatment guidelines created by recognized experts or professional associations. In the anesthesia profession, these weaknesses affect novices and specialists alike (Stiegler \& Tung). 
In a prospective, nonrandomized cohort study conducted by Munst et al., (2018), senior physician anesthesiologists selected an IV anesthetic that the authors termed "unjustified" based on accepted pharmacologic principles in one out of every three cases. Medical decisions should be based upon conditions specific to the patient and the procedure. Often, personal preference, facility custom, budgetary or other non-medical motivations take precedence over sound science and accepted standards of practice. Decisions made by assigning primacy to factors that are not based on sound pharmaceutical science and in the patients' best interest places patients at undue risk. This is true even if no harm comes to the patient, or any possible adverse reactions can be easily dispensed with by the anesthesia provider (Munst et al.).

Several decision-making models have been examined for the manner in which their tenets apply to the field of anesthesia (Stiegler \& Tung, 2014). A common theme in some of the oldest decision-making models is to consider the cost versus benefit of each medical decision and assess the potential consequences. Practitioners must be cognizant that all of the information necessary to make that determination may not be available. Patient and practitioner priorities may also differ (Stiegler \& Tung, 2014). Providers may gravitate toward the solution that can be accomplished in the least time with the least cost while not incurring undue risk, while the patient may prefer the safest, most comfortable option regardless of the cost or time involved.

Pattern-matching is commonly employed as a mechanism for decision-making and used as a framework in medical education (Stiegler \& Tung, 2014). Providers consider the decisions they have made, or they have seen others make in similar situations before without consequence, leading them to believe that the same decision is 
applicable in all similar circumstances. This, and other intellectual shortcuts, sacrifice rationality for convenience and thus risk grave errors in decision-making or failure to recognize a life-threatening situation (Stiegler \& Tung). This is especially noteworthy in situations where the provider lacks a complete information set related to the patient or procedure (Munst et al., 2018). Critical decisions in time-sensitive situations are more likely to be made purely on instinct, especially when the clinician feels that taking time to consider all possible choices and outcomes is impractical (Stiegler \& Tung, 2014).

A number of biases have been cited as root causes of medical errors and can weigh considerably on the decision-making process (Stiegler \& Tung, 2014). Human nature is to seek out information that confirms one's own conclusions rather than a perspective challenging the legitimacy of an action. In a collaborative practice environment, some providers may hesitate to question the decision of a senior colleague or offer an alternative therapy, even when armed with a vital piece of information. Experience and prestige can lead to excessive self-assuredness, blinding providers to the possibility of other choices or failure to seek assistance when necessary. This may be most evident when senior practitioners refuse to adopt a safer method of performing a skill for which they have realized historical success in the face of evidence demonstrating the superiority of the new method. Practitioners who draw their primary decision-making influence from past experience are also vulnerable to the idea that their memory does not mirror the details of the comparable event (Stiegler \& Tung).

Additional biases that influence decision-making relate to the manner in which the provider views the possible outcomes of the decision (Stiegler \& Tung, 2014). Emotion can play a significant role in decision-making. A provider may avoid a correct 
decision if they have experienced a negative outcome when using a particular intervention in a similar situation. Decisions believed to produce positive results will always be preferred to those believed to produce negative consequences (Stiegler \& Tung). There is considerable variability in how a negative experience influences a practitioner's future decision-making processes (Cozmuta et al., 2014). Particularly in the practice of anesthesia, there is little in the way of patient contact after discharge and a thorough case review is rarely undertaken absent an obvious complication or sentinel event. Lacking any information to the contrary, decisions will be assumed to have been correct and the desired outcome achieved (Stiegler \& Tung, 2014).

The rationale behind a clinical decision is equally important as the decision itself (Stiegler \& Tung, 2014). Making the correct decision based on reasoned thinking in context with training and experience develops competence. Choosing the correct intervention for the incorrect reason is simply a case of good luck and can easily lead to a different result under different circumstances. Understanding all of the factors that influence the decision-making process improves the likelihood that providers will recognize illogical factors influencing their behavior, guiding them to a more reasoned and scientifically based choice. The use of cognitive aids has been shown to minimize the likelihood that the decision-making process will be negatively prejudiced by outside factors more likely to lead to an incorrect judgement (Stiegler \& Tung). Decision trees are one such cognitive aid.

\section{Decision Trees in Evidence-Based Practice}

Decision trees provide a logical, orderly framework that can be used by clinicians to evaluate the factors that impact a decision and guide them to the appropriate choice 
(Lee et al., 2009). Appropriate utilization of evidence-based practice (EBP) is not merely the regurgitation of findings from a particular study and applying them to all patients.

The individual complexities of each patient and each situation requires clinical judgement to interpret the best evidence and relate it to the individual. Often, several decision points are navigated on the pathway to the eventual choice (Lee et al.).

Decision trees provide a mechanism for identifying the available options and considering the possible consequences of each step in the decision-making process (Bamber \& Evans, 2016). Even in the face of limited evidence, a properly tailored decision tree affords the clinician a mechanism for considering what is available without the need to perform a literature search on the spot. The evidence-based information in the decision tree serves to augment the knowledge and experience of the clinician and is superior to choosing a therapy on conjecture alone. The transparency provided is one of the decision tree's greatest assets. In some settings, the patient can be consulted to determine their priorities, and collaborate with the provider to provide safe, individualized care. Decision trees may be most beneficial in situations where there are few alternatives and the incorrect choice will put the patient in jeopardy (Bamber \& Evans). Implementation of a decision tree assists practitioners to consider all of the relevant facts, especially those that may not be routinely anticipated (Lee et al., 2009). Next, the theoretical framework will be presented. 


\section{Theoretical Framework}

The theoretical frameworks for this project were the Information-Processing Theory (IPT) and the Preferred Reporting Items for Systematic Reviews and MetaAnalyses (PRISMA). Initially applied to cognitive decision making in healthcare in the late 1970’s, IPT (Figure 1) encourages clinicians to consider theories for a particular situation, place them in context with a given set of variables, confirm or refute the theory, and utilize the best applicable information to guide care (Joseph \& Patel, 1990). Clinical information is collected and distilled through the clinician's body of knowledge and experience. These factors guide the initial plan, which is refined based on any other pertinent information the clinician seeks out. The applicability of each data point is considered and weighed in terms of its contribution to the whole and the processed information directs the decision. This framework assists clinicians in combining experience, diagnostic reasoning, scientific evidence, and logic to deduce the appropriate intervention from the options available and is commonly used in clinical decision-making and the creation of decision trees (Banning, 2008).

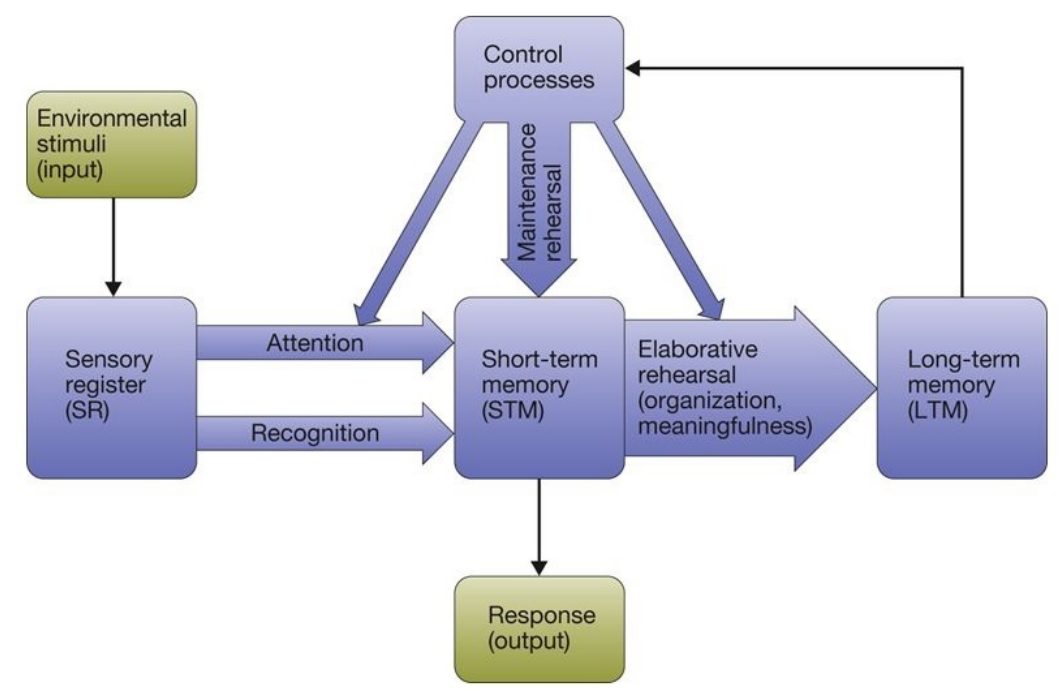

Figure 1. Information Processing Theory (Information Processing Model, n.d.) 
Information Processing Theory correlates to the concept of decision-making in anesthesia, as it parallels the traditional methods of information gathering and treatment selection in common use. A complete medical history is obtained for all patients receiving anesthesia as a standard of care (American Association of Nurse Anesthetists [AANA], 2019). Anesthetists begin to formulate their treatment plan based upon the information obtained. The anesthetist then conducts an in-person interview and physical assessment of the patient to gather additional pertinent information. The body of clinical data is reviewed in the context of the planned surgical procedure, and with the exception of any unforeseen circumstance that requires modification, the plan of care is finalized (AANA).

The current pace of turnover in the operating theater is one of many factors that contributes to lapses in patient safety, medication errors and other adverse events (Eichhorn, 2013). In situations of increased pressure, people take short cuts. Medication selection may be determined based on comfort of the anesthesia provider rather than what is best for the patient. The induction phase is a crucial time in anesthesia care during which errors in judgement can prove fatal to a patient. Utilizing the tenets of IPT, the preliminary steps can be undertaken to create an evidence-based decision tree to guide in the selection of an appropriate intravenous anesthetic for patients undergoing cardiac surgery.

Additionally, the Preferred Reporting Items for Systematic Reviews and MetaAnalyses (PRISMA) was used. Adapted from the Quality of Reporting of Meta-analyses (QUORUM) statement, PRISMA provides a comprehensive process through which an author can identify, track, evaluate and report relevant research obtained through 
randomized controlled trials (RCTs) (Moher, Liberati, Tetzlaff, Martin, \& The PRISMA Group, 2009).

Preferred Reporting Items for Systematic Reviews and Meta-Analyses utilizes a flow diagram (Figure 2) to assist the author in reporting the process used to select the studies used to complete a systematic review (Moher et al., 2009). The flow diagram is useful in demonstrating the breadth of the literature search conducted as well as accounting for the dispensation of any studies excluded from the review. Preferred Reporting Items for Systematic Reviews and Meta-Analyses also utilizes a 27-question checklist (Figure 3) for reporting on each research study included in a systematic review (Moher et al.). The deployment of this checklist ensures that a consistent and transparent process is used, so that reporting for each study is similar. Transparency in the research process, combined with consistency in evaluation and reporting of included studies, lowers the likelihood of publication bias (Moher et al.).

Next, the methods used to conduct this project will be described. 


\section{PRISMA 2009 Flow Diagram}

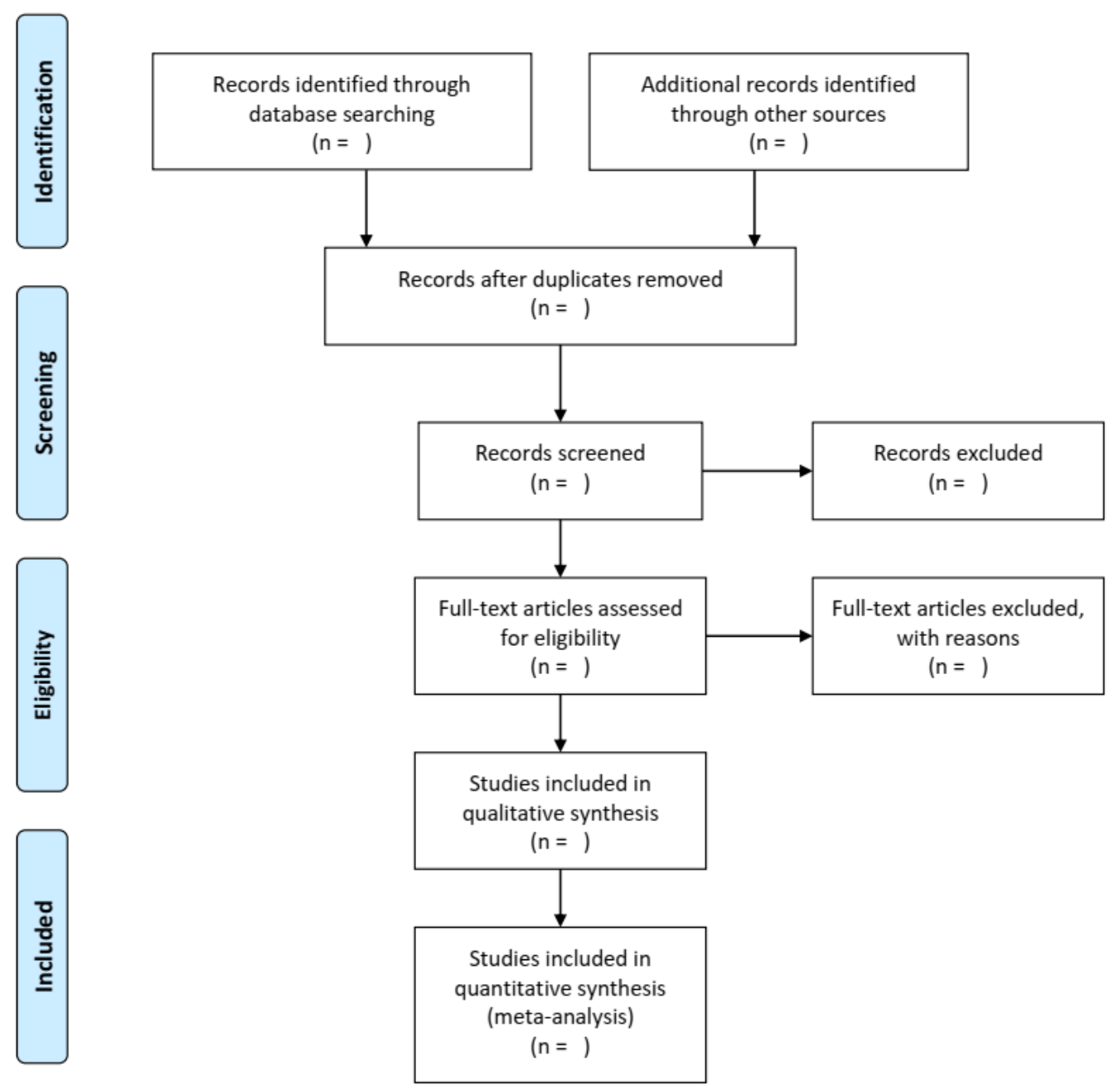

From: Moher D, Liberati A, Tetzlaff J, Altman DG, The PRISMA Group (2009). Preferred Reporting /tems for Systematic Reviews and MetaAnalyses: The PRISMA Statement. PLoS Med 6(7): e1000097. doi:10.1371/journal.pmed1000097

Figure 2. PRISMA flow diagram 


\begin{tabular}{|c|c|c|c|}
\hline Section/topic & $\#$ & Checklist item & $\begin{array}{l}\text { Reported } \\
\text { on page \# }\end{array}$ \\
\hline \multicolumn{4}{|l|}{ TITLE } \\
\hline Title & 1 & Identify the report as a systematic review, meta-analysis, or both. & \\
\hline \multicolumn{4}{|l|}{ ABSTRACT } \\
\hline $\begin{array}{l}\text { Structured } \\
\text { summary }\end{array}$ & 2 & $\begin{array}{l}\text { Provide a structured summary including, as applicable: background; objectives; data sources; study eligibility } \\
\text { criteria, participants, and interventions; study appraisal and synthesis methods; results; limitations; conclusions } \\
\text { and implications of key findings; systematic review registration number. }\end{array}$ & \\
\hline \multicolumn{4}{|l|}{ INTRODUCTION } \\
\hline Rationale & 3 & Describe the rationale for the review in the context of what is already known. & \\
\hline Objectives & 4 & $\begin{array}{l}\text { Provide an explicit statement of questions being addressed with reference to participants, interventions, } \\
\text { comparisons, outcomes, and study design (PICOS). }\end{array}$ & \\
\hline \multicolumn{4}{|l|}{ METHODS } \\
\hline $\begin{array}{l}\text { Protocol and } \\
\text { registration }\end{array}$ & 5 & $\begin{array}{l}\text { Indicate if a review protocol exists, if and where it can be accessed (e.g., Web address), and, if available, } \\
\text { provide registration information including registration number. }\end{array}$ & \\
\hline Eligibility criteria & 6 & $\begin{array}{l}\text { Specify study characteristics (e.g., PICOS, length of follow-up) and report characteristics (e.g., years } \\
\text { considered, language, publication status) used as criteria for eligibility, giving rationale. }\end{array}$ & \\
\hline $\begin{array}{l}\text { Information } \\
\text { sources }\end{array}$ & 7 & $\begin{array}{l}\text { Describe all information sources (e.g., databases with dates of coverage, contact with study authors to identify } \\
\text { additional studies) in the search and date last searched. }\end{array}$ & \\
\hline Search & 8 & $\begin{array}{l}\text { Present full electronic search strategy for at least one database, including any limits used, such that it could be } \\
\text { repeated. }\end{array}$ & \\
\hline Study selection & 9 & $\begin{array}{l}\text { State the process for selecting studies (i.e., screening, eligibility, included in systematic review, and, if } \\
\text { applicable, included in the meta-analysis). }\end{array}$ & \\
\hline $\begin{array}{l}\text { Data collection } \\
\text { process }\end{array}$ & 10 & $\begin{array}{l}\text { Describe method of data extraction from reports (e.g., piloted forms, independently, in duplicate) and any } \\
\text { processes for obtaining and confirming data from investigators. }\end{array}$ & \\
\hline Data items & 11 & $\begin{array}{l}\text { List and define all variables for which data were sought (e.g., PICOS, funding sources) and any assumptions } \\
\text { and simplifications made. }\end{array}$ & \\
\hline $\begin{array}{l}\text { Risk of bias in } \\
\text { individual studies }\end{array}$ & 12 & $\begin{array}{l}\text { Describe methods used for assessing risk of bias of individual studies (including specification of whether this } \\
\text { was done at the study or outcome level), and how this information is to be used in any data synthesis. }\end{array}$ & \\
\hline $\begin{array}{l}\text { Summary } \\
\text { measures }\end{array}$ & 13 & State the principal summary measures (e.g., risk ratio, difference in means). & \\
\hline $\begin{array}{l}\text { Synthesis of } \\
\text { results }\end{array}$ & 14 & $\begin{array}{l}\text { Describe the methods of handling data and combining results of studies, if done, including measures of } \\
\text { consistency }\left(e . g ., 1^{2}\right) \text { for each meta-analysis. }\end{array}$ & \\
\hline $\begin{array}{l}\text { Risk of bias } \\
\text { across studies }\end{array}$ & 15 & $\begin{array}{l}\text { Specify any assessment of risk of bias that may affect the cumulative evidence (e.g., publication bias, selective } \\
\text { reporting within studies). }\end{array}$ & \\
\hline $\begin{array}{l}\text { Additional } \\
\text { analyses }\end{array}$ & 16 & $\begin{array}{l}\text { Describe methods of additional analyses (e.g., sensitivity or subgroup analyses, meta-regression), if done, } \\
\text { indicating which were pre-specified. }\end{array}$ & \\
\hline \multicolumn{4}{|l|}{ RESULTS } \\
\hline Study selection & 17 & $\begin{array}{l}\text { Give numbers of studies screened, assessed for eligibility, and included in the review, with reasons for } \\
\text { exclusions at each stage, ideally with a flow diagram. }\end{array}$ & \\
\hline $\begin{array}{l}\text { Study } \\
\text { characteristics }\end{array}$ & 18 & $\begin{array}{l}\text { For each study, present characteristics for which data were extracted (e.g., study size, PICOS, follow-up period) } \\
\text { and provide the citations. }\end{array}$ & \\
\hline $\begin{array}{l}\text { Risk of bias within } \\
\text { studies }\end{array}$ & 19 & Present data on risk of bias of each study and, if available, any outcome level assessment (see item 12). & \\
\hline $\begin{array}{l}\text { Results of } \\
\text { individual studies }\end{array}$ & 20 & $\begin{array}{l}\text { For all outcomes considered (benefits or harms), present, for each study: (a) simple summary data for each } \\
\text { intervention group (b) effect estimates and confidence intervals, ideally with a forest plot. }\end{array}$ & \\
\hline $\begin{array}{l}\text { Synthesis of } \\
\text { results }\end{array}$ & 21 & Present results of each meta-analysis done, including confidence intervals and measures of consistency. & \\
\hline $\begin{array}{l}\text { Risk of bias } \\
\text { across studies }\end{array}$ & 22 & Present results of any assessment of risk of bias across studies (see ltem 15). & \\
\hline Additional analysis & 23 & $\begin{array}{l}\text { Give results of additional analyses, if done (e.g., sensitivity or subgroup analyses, meta-regression [see Item } \\
\text { 16]). }\end{array}$ & \\
\hline \multicolumn{4}{|l|}{ DISCUSSION } \\
\hline $\begin{array}{l}\text { Summary of } \\
\text { evidence }\end{array}$ & 24 & $\begin{array}{l}\text { Summarize the main findings including the strength of evidence for each main outcome; consider their relevance } \\
\text { to key groups (e.g., healthcare providers, users, and policy makers). }\end{array}$ & \\
\hline Limitations & 25 & $\begin{array}{l}\text { Discuss limitations at study and outcome level (e.g., risk of bias), and at review-level (e.g., incomplete retrieval } \\
\text { of identified research, reporting bias). }\end{array}$ & \\
\hline Conclusions & 26 & $\begin{array}{l}\text { Provide a general interpretation of the results in the context of other evidence, and implications for future } \\
\text { research. }\end{array}$ & \\
\hline \multicolumn{4}{|l|}{ FUNDING } \\
\hline Funding & 27 & $\begin{array}{l}\text { Describe sources of funding for the systematic review and other support (e.g., supply of data); role of funders for } \\
\text { the systematic review. }\end{array}$ & \\
\hline
\end{tabular}

From: Moher D, Liberati A, Tetzlaff J, Altman DG, The PRISMA Group (2009). Preferred Reporting Items for Systematic Reviews and Meta-Analyses: The PRISMA Statement. PLoS Med 6(7): e1000097. doi:10.1371/joumal.pmed1000097

\section{Figure 3. PRISMA checklist}




\section{Method}

\section{Purpose}

The purpose of this paper was to propose a preliminary, evidence-based decision tree to guide in the selection of an appropriate intravenous anesthetic for patients undergoing cardiac surgery.

\section{Design}

This was an evidence-based project designed to create a decision tree. Evidence was gathered, evaluated, analyzed, and reported in a manner similar to that which is used to perform a systematic review.

\section{Inclusion/Exclusion Criteria}

Inclusion criteria for this systematic review included RCTs only. All patients included in the trial were required to be adults (greater than 18 years of age), be undergoing cardiac surgery with no other included procedure, and have anesthesia induced via the intravenous route utilizing a single intravenous anesthetic. All patients must have received either propofol, etomidate, or ketamine for induction. All of the RCTs must have been published within the last ten years, written in English, and published in a peer-reviewed journal.

Exclusion criteria included any article published greater than 10 years ago or written in a language other than English. Additional exclusion criteria included any patients under age 18, patients receiving an inhalation induction, studies that don't compare propofol, etomidate or ketamine to one of the other of these three medications, and any patient receiving any combination of intravenous anesthetics. 


\section{Search Strategy}

A comprehensive literature search was conducted utilizing the databases CINAHL, Academic Search Premier, Medline and PubMed. Search terms included "induction of anesthesia", "propofol”, “etomidate”, "ketamine”, “cardiac surgery", and “coronary artery bypass grafting”. After removing duplicates, articles were screened for eligibility. Articles meeting eligibility criteria were included in the data collection process. The search process and results were summarized in a PRISMA Flow Diagram (Appendix A).

\section{Data Collection}

Studies selected for this systematic review were evaluated utilizing the PRISMA Checklist as a guide. Data collected from each study was summarized in a table created by the author (Table 1) and included in Appendix B.

\section{Table 1}

Data Collection Table

\begin{tabular}{|c|c|c|c|c|c|}
\hline Purpose & $\begin{array}{c}\text { Project } \\
\text { Design }\end{array}$ & Site, Sample & Method & Results & Limitations \\
\hline & & & & & \\
\hline
\end{tabular}

Outcome measures for each study were extracted and summarized in a table created by the author (Table 2), illustrated on the next page, and included in Appendix C. 


\section{Table 2}

Outcome Measures Table

\begin{tabular}{|c|c|c|c|}
\hline & Propofol & Etomidate & Ketamine \\
\hline Heart Rate & & & \\
\hline Systolic Blood Pressure & & & \\
\hline Diastolic Blood Pressure & & & \\
\hline Mean Arterial Pressure & & & \\
\hline Cardiac Output & & & \\
\hline Cardiac Index & & & \\
\hline SVR & & & \\
\hline Endocrine Response & & & \\
\hline
\end{tabular}

\section{Critical Appraisal}

Critical appraisal of each study was carried out using the Critical Appraisal Skills Programme (CASP). Critical Appraisal Skills Programme was developed to assist researchers by providing an organized method for evaluating evidence to determine quality (Singh, 2013). When using evidence to change practice, the recommendations are only as strong as the evidence used. Critical appraisal of research gauges the reliability of the methodology and findings of a study. Studies conducted using the incorrect methods for the study design, improper statistical analysis techniques, and suspect reporting practices are not acceptable for the basis of guiding clinical practice. Each study was critically appraised utilizing the CASP checklist shown in Table 3 and included in Appendix D. 
Table 3

CASP Checklist for Randomized Controlled Trials

A) Are the results of the trial valid?

1. Did the trial address a clearly focused issue?

2. Was the assignment of patients to treatments randomized?

3. Were all of the patients who entered the trial properly accounted for at its conclusion?

4. Were patients, health workers, and study personnel "blind" to treatment?

5. Were the groups similar at the start of the trial?

6. Aside from the experimental intervention, were groups treated equally?

B) What are the results?

7. How large was the treatment effect?

8. How precise was the estimate of the treatment effect?

C) Will the results help locally?

9. Can the results be applied in your context? (or to the local population?)

10. Were all clinically important outcomes considered?

11. Are the benefits worth the harms?
YES

CAN'T TELL

NO

\section{YES CAN'T TELL NO}

\section{Cross-Study Analysis}

Results were analyzed across studies utilizing Table 2 to determine overall outcomes, themes and significance of findings. The findings of the cross-study analysis were utilized to guide the preliminary creation of an evidence-based decision tree to guide in the selection of an appropriate intravenous anesthetic for patients undergoing cardiac surgery. The process used will be described in the results section.

Next, the results will be presented. 


\section{Results}

Based upon the inclusion and exclusion criteria explained above, nine articles were identified and included in this review. The process used to identify, screen, and select the included articles is represented graphically in Appendix A. All of the included articles are RCTs comparing one of the chosen IV anesthetics to another of the chosen IV anesthetics during the induction phase of general anesthesia. Study-specific data were extracted from each article and are included in Appendix B. Outcome measures and results were extracted from each article and are included in Appendix C. Each article was evaluated for quality using the CASP Checklist for Randomized Controlled Trials, which are included in Appendix D. Finally, a cross-study analysis was performed to compare and contrast the findings of each article and is included in Appendix E.

\section{Individual Study Analysis}

The study performed by Basagan-Mogol et al. (2010) (Appendix B-1) was a randomized controlled trial to evaluate the hemodynamic and analgesic effects of ketamine by comparing it with propofol. All patients were undergoing CABG procedures. Thirty patients were randomly assigned to two groups. Patients assigned to group $\mathrm{K}$ received $2 \mathrm{mg} / \mathrm{kg}$ of ketamine as their IV induction agent. Patients assigned to group $\mathrm{P}$ received $0.5 \mathrm{mg} / \mathrm{kg}$ of propofol as their IV induction agent. All patients received standardized weight-based doses of morphine, midazolam, fentanyl, and rocuronium during the induction process. Laryngoscopy was performed and intubation was achieved using the same process in all patients. All patients were monitored using the same invasive and non-invasive modalities. Anesthesia was maintained utilizing 0.5$2 \%$ sevoflurane. Adjustments to sevoflurane doses were made based upon the same 
hemodynamic parameters in all patients. Data were recorded at the same time intervals in all patients.

Data were analyzed using the SPSS software platform to determine the mean and standard deviation for each outcome measure. The Wilcoxon signed rank test was used to evaluate deviations from baseline for each outcome measure. The Mann-Whitney Utest and the Kruskal Wallis test were used to compare values between the study groups. The authors defined $\mathrm{p}<0.05$ as significant. The authors found significant decreases in MAP and SVR one minute after induction in group P (Appendix C-1). The authors reported that there were no adverse hemodynamic events or ST-segment abnormalities during the study, nor was any evidence found that ketamine clearly contributed to the level of analgesia.

Critical appraisal of this study can be found in Appendix D-1. The study addressed a clearly focused issue. The assignment of patients to each group was randomized and all patients were properly accounted for at the conclusion of the trial. There was no indication as to the method used to randomize the participants, nor was there any indication that the patient or anesthesia providers were blinded to the study medication. The article does report that the observer responsible for recording measurements was blinded to the study medication. The groups were similar, and with the exception of the experimental intervention, the groups were treated equally. The treatment effect was not discussed. The results can be applied to the local population. All clinically important outcomes were considered. No harmful effects were reported from the study intervention. Based upon their findings, the authors concluded that ketamine provided more hemodynamic stability, and was therefore superior to propofol. 
The study by Pandey et al. (2012) (Appendix B-2) was a randomized controlled trial in which the effects of propofol on hemodynamic parameters and serum cortisol levels were compared with etomidate in patients with normal left ventricular function. All patients were undergoing elective $\mathrm{CABG}$ procedures on cardiopulmonary bypass (CPB). One hundred patients were randomly assigned to two groups. Patients assigned to group E received $0.2 \mathrm{mg} / \mathrm{kg}$ of etomidate as the IV induction agent. Patients assigned to group P received $2.0 \mathrm{mg} / \mathrm{kg}$ or propofol as the IV induction agent. All patients received similar weight-based doses of morphine, phenergan, midazolam, fentanyl, and rocuronium, which were administered within the same time frame prior to and during the induction process. All patients were monitored using the same invasive and non-invasive modalities. Once induced, anesthesia was maintained using sevoflurane. Data points were recorded for the same hemodynamic parameters and cortisol levels at the same time intervals respectively for all patients.

Statistical analysis was performed using the STATA 9.0 software platform and data were summarized using a percentage or a range as the particular parameter required. Baseline categorical variables were compared using the Fisher's exact test. Baseline continuous variables were compared using the Student's t test. Between-group hemodynamic variables were compared using the Student's t test for independent variables. The Wilcoxon Rank Sum test was used to analyze between-group data concerning serum cortisol. The authors identified a value of $\mathrm{p}<0.05$ as a significant finding. Outcome measures can be found in Appendix C-2. The authors reported a significant decrease in SBP, DBP, SVR and SVRI five minutes after induction in group $\mathrm{P}$. The authors also reported a significant decrease in cortisol levels in group $\mathrm{E}$ and a 
significant increase in cortisol levels in group P during weaning from CPB. The authors further determined that etomidate provided more stable hemodynamics than propofol $(\mathrm{p}<$ $0.05)$.

Critical appraisal of this study can be found in Appendix D-2. The study addressed a clearly focused issue. The assignment of patients to treatments was randomized by a computer and performed as a component of the registration process prior to the procedure in an outpatient department. All patients who entered the trial were accounted for. While the assignment to treatment was randomized, the article does not report on who, if anyone, was blinded. The groups were similar at the start of the trial and were treated equally, with the exception of the experimental intervention. The treatment effect was not discussed. The results of the study can be applied to the local population. All clinically important outcomes were considered. No harmful effects were attributed to the study intervention. Based upon their findings, the authors concluded that etomidate provided more stable hemodynamics during induction when compared with propofol and that etomidate can be used safely for induction of anesthesia for CABG on $\mathrm{CPB}$ in patients with good left ventricular function. The authors further concluded that serious decreases in serum cortisol levels produced by etomidate do not last more than 24 hours.

The study performed by Kaushal, Vatal, and Pathak (2015) (Appendix B-3) was a prospective, randomized study to compare induction with etomidate and propofol in cardiac surgeries. All patients were undergoing CABG, mitral valve replacement (MVR), or aortic valve replacement (AVR) on CPB. Sixty patients were randomly assigned to two groups. Patients assigned to group I received $2 \mathrm{mg} / \mathrm{kg}$ of propofol as the 
IV induction agent. Patients in group II received $0.2 \mathrm{mg} / \mathrm{kg}$ of etomidate as the IV induction agent. All patients received similar doses of glycopyrrolate, midazolam, ranitidine, ondansetron, and fentanyl within the same time frame prior to and during the induction process. All patients were monitored using the same invasive and non-invasive monitoring modalities. Data points were recorded for the same hemodynamic parameters and cortisol levels at the same time intervals respectively for all patients.

The statistical analysis program utilized by the authors was not reported. Data were compiled and summarized by reporting the percentage or range as appropriate for the particular data point. Baseline categorical between-group variables were compared using Fisher's exact test. Baseline between-group continuous variables were compared using Student's t-test. Between-group hemodynamic variables were compared using Student's t-test for independent variables. Between-group comparison of cortisol data was performed using the Wilcoxon Rank Sum test. The authors identified a value of $\mathrm{p}<$ 0.05 as a significant finding. Outcome measures can be found in Appendix C-3. The authors reported a significant decrease in SBP, DBP, MAP, CO, and CI after induction, after intubation, and five minutes post-intubation in group I. After intubation, SVR continued to decrease in group I while it increased above baseline in group II. The authors further reported that serum cortisol decreased significantly in group II while increasing significantly in group I. Serum cortisol in both groups returned to baseline levels 24 hours post-operatively $(\mathrm{p}<0.001)$.

Critical appraisal of this study can be found in Appendix D-3. The trial addressed a clearly focused issue. The assignment of patients to treatment was randomized. All patients who entered the trial were accounted for. The authors reported that 
randomization was performed by opening a sealed envelope containing the group assignment immediately prior to entering the operating room. The degree to which patients, health workers, and study personnel were blind to treatment was not specifically addressed. The methods used to assign particular patients to a particular group were not discussed. Upon opening the envelope, the anesthesia provider would be aware which medication would be administered to the patient; however they would have not had any forewarning. The groups were similar at the start of the trial and were treated equally with the exception of the experimental intervention. The treatment effect was not discussed. The results can be applied to the local population. All clinically important outcomes were considered. No harmful or adverse outcomes were reported. The authors concluded that etomidate provided a more stable hemodynamic profile during the induction of anesthesia for patients with poor LV function when compared with propofol and that any observed fluctuation in cortisol levels did not result in untoward effects. Based upon their findings the authors determined that etomidate can be used safely for induction of anesthesia for CABG, MVR, or AVR procedures on CPB in patients with poor left ventricular function.

A study performed by Shivanna et al. (2015) (Appendix B-4) was a prospective, double blind, randomized comparative study to evaluate the hemodynamic effects of etomidate in comparison to that of propofol during induction of general anesthesia. All patients were undergoing $\mathrm{CABG}$ on $\mathrm{CPB}$. Forty patients were randomly assigned to two groups. Induction was carried out using an infusion of the assigned medication rather than a single bolus dose. Patients in group P received $0.5 \mathrm{mg} / \mathrm{kg} / \mathrm{min}$ of propofol as the IV induction agent. Patients in group E received $0.05 \mathrm{mg} / \mathrm{kg} / \mathrm{min}$ of etomidate as the IV 
induction agent. All patients received similar doses of morphine, promethazine, midazolam, fentanyl, and rocuronium within the same time frame prior to or during the induction process. All patients were monitored using the same invasive and non-invasive monitoring modalities. Anesthesia was maintained using sevoflurane in all patients. Hemodynamic fluctuations were treated utilizing the same parameters and same interventions for all patients. Data points were recorded for the same hemodynamic parameters at the same time intervals in all patients.

Statistical analysis was performed using the SPSS, STATA, Med Calc, and Systat software platforms. Patient characteristics were examined using the Chi-square test. Between-group comparison was performed using the unpaired t-test. The authors delineated three different levels of significance. A p-value of 0.05-0.10 was categorized as having "suggestive significance". A p-value of 0.01-0.05 was categorized as "moderately significant". A p-value $<0.01$ was categorized as "strongly significant". The authors performed a power analysis of previous studies to determine that a sample size of 20 patients per group was required to achieve a power of $80 \%$ and a 0.05 for detection of the desired hemodynamic changes. Outcome measures can be found in Appendix C-4. The authors reported that MAP decreased in group P more than group E; however the difference was not statistically significant. The authors reported that SVR decreased in group $\mathrm{P}$ in a moderately significant manner $(\mathrm{p}=0.022)$. The authors further reported that after intubation, SVR increased in both groups, with the patients in group $\mathrm{E}$ demonstrating a statistically significant larger increase than group $\mathrm{P}(\mathrm{p}=0.003)$.

Critical appraisal of this article can be found in Appendix D-4. The study addressed a clearly focused issue. The assignment of patients was randomized. All 
patients who entered the study were accounted for. Participants were blinded to the treatment. The groups were similar at the start of the trial. The groups were treated equally, with the exception of the experimental intervention. The treatment effect was not discussed. The results can be applied to the local population. All clinically important outcomes were considered. No harmful or untoward events were reported. Based upon their findings, the authors concluded that propofol produced a greater reduction in contractility, arterial blood pressure, and afterload when compared with etomidate when used as an induction agent in patients with coronary artery disease. The authors further concluded that etomidate was less effective than propofol in preventing a patient's stress response to intubation.

A study performed by Kamath, Kamath and Patla (2016) (Appendix B-5) was a prospective, randomized study to compare propofol with etomidate with respect to hemodynamic stability during induction of anesthesia for open cardiac surgical procedures. All study participants were undergoing elective cardiac surgical procedures, which included CABG, MVR, and AVR. Sixty patients were randomly assigned to two groups. Group A received $1.5 \mathrm{mg} / \mathrm{kg}$ of propofol as the IV induction agent. Group B received $0.2 \mathrm{mg} / \mathrm{kg}$ of etomidate as the IV induction agent. All patients received similar actual or weight-based doses of ranitidine, diazepam, fentanyl, midazolam, and rocuronium prior to or during the induction process. After the induction agents and all other adjuncts were administered, all patients were ventilated with $100 \%$ oxygen and $1 \%$ sevoflurane for three minutes prior to intubation. All patients were monitored using identical invasive and non-invasive monitoring modalities. Data points were collected for the same hemodynamic parameters at the same time intervals for all patients. 
Statistical analysis was performed utilizing the SPSS software platform. Baseline values were compared using the independent Student's t-test. Continuous variables were compared using the independent Student's t-test. The authors identified a p-value of $<$ 0.05 as a significant finding. Outcome measures can be found in Appendix C-5. The authors reported a significant decrease in SBP, MAP, CO and CI after induction in group A. The authors reported a significant increase in DBP, CO and CI after intubation in group A. The authors reported a significant increase in MAP, CVP and PCWP five minutes after intubation in group A. No significant changes were noted in group B for any data point at any time.

Critical appraisal for this article can be found in Appendix D-5. The article addressed a clearly focused issue. The assignment of patients was randomized using closed envelope technique. All patients who entered the trial were properly accounted for. It was not clear from the article whether patients, health care workers, or study personnel were blind to treatment. Groups were similar at the start of the trial. All participants were treated equally, with the exception of the experimental intervention. Treatment effect was not discussed. The results can be applied to the local population. All clinically important outcomes were considered. No harmful or untoward effects were reported. Based upon their findings, the authors concluded that etomidate provides a more favorable hemodynamic profile when compared with propofol when used for induction of anesthesia in cardiac surgical procedures.

A study performed by Soleimani et al. (2017) (Appendix B-6) was a double-blind, randomized clinical study to compare the hemodynamic responses to propofol, etomidate, and diazepam following anesthesia induction, laryngoscopy, and intubation in patients 
with low ejection fraction. While this study investigated a medication outside the scope of this paper (diazepam), the authors reported data specifically comparing the hemodynamic responses to propofol and etomidate, which is directly applicable and meets the inclusion criteria. All study participants were undergoing elective CABG with CPB. One hundred fifty patients were randomly assigned to three equal groups. Patients in group A received $1.5 \mathrm{mg} / \mathrm{kg}$ of propofol as the IV induction agent. Patients in group B received $0.2 \mathrm{mg} / \mathrm{kg}$ of etomidate as the IV induction agent. Patients in group $\mathrm{C}$ received $0.3 \mathrm{mg} / \mathrm{kg}$ of diazepam as the IV induction agent. All patients received identical weightbased doses of midazolam, fentanyl, and succinylcholine during the induction process. All patients were monitored utilizing the same invasive and non-invasive monitoring modalities. Data points were collected for the same hemodynamic parameters at the same time intervals for all patients.

Statistical analysis was performed utilizing the SPSS software platform. Normal distribution of data determination was performed using the Kolmogorov-Smirnov test. Quantitative variable analysis was performed using ANOVA and the Bonferroni test. The authors identified a p-value $<0.05$ as a significant finding. Outcome measures can be found in Appendix C-6. The authors reported a significant decrease in SBP, DBP, and MAP in groups $\mathrm{A}, \mathrm{B}$, and $\mathrm{C}$ one minute after induction and before laryngoscopy, with the reductions in group $\mathrm{C}$ being to a lesser degree than groups $\mathrm{A}$ and $\mathrm{B}$. These measurements returned to near baseline in groups $\mathrm{B}$ and $\mathrm{C}$ while remaining significantly reduced in group A one minute after laryngoscopy. The authors reported a significant decrease in mean HR one minute after induction in groups $\mathrm{A}$ and $\mathrm{B}$, which did not occur in group $\mathrm{C}$. 
The authors reported that a significantly larger percentage of patients in group A required rescue administration of ephedrine when compared with groups $\mathrm{B}$ and $\mathrm{C}$.

Critical appraisal for this article can be found in Appendix D-6. The study addressed a clearly focused issue. The assignment of patients to treatments was randomized using the sealed envelope technique. Allocation to a particular group was performed based upon a numbers list that was computer-generated by a nurse who was unaware of the study groups. All patients who entered the trial were accounted for at its conclusion. All participants, including the anesthesia provider of record, were blinded to the treatment. To ensure patient safety, medications were prepared by a qualified anesthesia provider who was not involved in the study. Each of the study medications was prepared in an equal volume and syringes were covered with tape to conceal any identifying characteristics of the medication contained within. The groups were similar at the start of the trial and were treated equally, with the exception of the experimental intervention. Treatment effect was not discussed. The results can be applied to the local population. Diazepam is not traditionally used as an IV induction agent. The data reported comparing propofol and etomidate are directly applicable to this paper. All clinically relevant outcomes were considered. No harmful or untoward events were reported. The authors' conclusion was that diazepam provided more favorable hemodynamics than propofol and etomidate. The extraction of data comparing propofol and etomidate demonstrated that propofol results in a greater decrease in SBP, DBP, and MAP when compared to etomidate and the decrease continues for a greater length of time in patients receiving propofol. This is consistent with the substantially greater need for 
rescue administration of ephedrine for patients receiving propofol $(28 \%)$ compared with those receiving etomidate $(4 \%)$.

A study performed by Mala and Narmada (2017) (Appendix B-7) was a prospective, randomized study to compare the hemodynamic profile and hormonal alteration between etomidate and propofol following induction of anesthesia. All patients included in this study were undergoing elective CABG with CPB. Thirty patients were randomly assigned to two equal groups. Patients in the propofol group received $2 \mathrm{mg} / \mathrm{kg}$ of propofol as the IV induction agent. Patients in the etomidate groups received 0.2 $\mathrm{mg} / \mathrm{kg}$ as the IV induction agent. All patients were monitored utilizing the same invasive and non-invasive monitoring modalities. Data were collected for the same hemodynamic parameters at the same time intervals for all patients.

The authors reported that statistical analysis was performed, however the methods used were not reported. The authors identified a $\mathrm{p}$-value $<0.05$ as a significant finding. Outcome measures can be found in Appendix C-7. The authors reported a significant reduction in SBP compared to baseline in the propofol group after induction, which was much lower five minutes after intubation. The authors reported a significant decrease in CI from baseline in the propofol group when measured two and three minutes following induction. The authors reported a 50\% decrease in serum cortisol at the initiation of CPB in the etomidate group, while serum cortisol in the propofol group was nearly double the baseline level.

Critical appraisal of this article can be found in Appendix D-7. The trial addressed a clearly focused issue. The authors reported that assignment of patients to treatments was randomized; however, the randomization method was not provided. The 
authors reported that the patients were randomly assigned to two groups, but there was no further discussion as to the disposition of these patients. The groups were similar at the start of the trial. The treatment regimen outside of the experimental intervention was not discussed. The authors neither stated that the regimen was the same across all patients, nor stated that it was different. Treatment effect was not discussed. The results can be applied to the local population. All clinically important outcomes were considered. No harmful or untoward events were reported. Based upon their findings, the authors concluded that induction with etomidate provided more hemodynamic stability when compared with propofol. The authors reported that etomidate caused a transient reduction in serum cortisol which normalizes within two hours. The authors conclusory statement was that etomidate can therefore be used safely for induction of anesthesia in patients with good left ventricular function for CABG with CPB.

A study performed by Meena et al. (2017) (Appendix B-8) was a prospective randomized study to compare the effects of etomidate and propofol on hemodynamic and serum cortisol levels. All patients included in the study were undergoing elective CABG with CPB. Sixty patients were randomized into two equal groups. Patients in group A received $0.3 \mathrm{mg} / \mathrm{kg}$ of etomidate as their IV induction agent. Patients in group B received $2.0 \mathrm{mg} / \mathrm{kg}$ of propofol as their IV induction agent. All patients received similar weightbased doses of morphine, promethazine, fentanyl and rocuronium prior to or during the induction process at the same time intervals. All patients were monitored using the same invasive and non-invasive monitoring modalities. Data were collected for the same hemodynamic parameters and serum levels at the same time intervals for all patients. 
Statistical analysis was performed utilizing the SPSS software platform. Quantitative measurements were reported with means and standard deviations. The unpaired t-test was used to analyze the between-group difference between the means. The paired t-test was used to analyze the within-group difference between the means. The authors reported qualitative data, which only includes patient age, as a number and percentage. The chi square test was used to analyze the differences in qualitative data. The authors maintained a significance level of $95 \%$ for all analyses. Outcome measures can be found in Appendix C-8. The authors reported a significant decrease in SBP, DBP, SVR and SVRI in group B after induction. The authors reported a significant increase in HR and SBP after intubation in group A. The authors reported a significant decrease in serum cortisol when coming off bypass in group A, with a significant increase in group B.

Critical analysis of this article can be found in Appendix D-8. The trial addressed a clearly focused issue. The assignment of patients to treatments was randomized. Randomization was performed using the chit-in-box method. All patients were accounted for at the trial's conclusion. The authors did not report on the blinding of any participants. The groups were similar at the start of the trial. While the calculated distribution of patients according to sex was not statistically significant, $85 \%$ of the patients enrolled in the study were male. In group A, there were only two females, while in group B, there were only seven females. The authors reported that there were no statistically significant differences between groups; however, the within-group gender distribution is noteworthy. The groups were treated equally, with the exception of the experimental intervention. Treatment effect was not discussed. The results can be 
applied to the local population. All clinically important outcomes were considered. The authors reported four instances of pain with injection, one instance of severe hypotension, and two instances of bradycardia in group B, and 2 instances of myoclonus in group A. Based upon their findings, the authors concluded that etomidate prevented the surge in serum cortisol at the institution of CPB that is seen when propofol is used and that etomidate produced a more stable hemodynamic profile than propofol during induction without blunting the sympathetic stimulation to laryngoscopy.

A study performed by Hannam et al. (2019) (Appendix B-9) was a randomized controlled superiority trial to test the hypothesis that etomidate is superior to propofol for induction of anesthesia in relation to hemodynamic stability over the first 10 minutes after induction in patients undergoing cardiac surgery. All patients enrolled in the study were undergoing elective $\mathrm{CABG}$, valve surgery, $\mathrm{CABG} / \mathrm{valve}$ surgery, and thoracic aorta surgery. One hundred fifty patients were enrolled in the study, which was conducted in two phases. Initially, 156 patients were randomized. After randomization, six patients were not included in the final results. The authors reported that four patients were excluded just prior to surgery, while two were not included due to corrupted electronic medical records. Each phase included two patient groups, each of which were randomized to receive either propofol or etomidate as the IV induction agent. Randomization was completed prior to the start of phase I, resulting in sample size variation between and within phases. The first phase was open-label, during which the anesthesia provider was not blinded to the treatment drug $(n=76$; propofol $=40$, etomidate $=36$ ). The second phase was closed-label, during which all clinical staff were blinded $(\mathrm{n}=74 ;$ propofol $=35$, etomidate $=39)$. All patients received midazolam, 
fentanyl, and a non-specific non-depolarizing neuromuscular blocking medication prior to or during the induction process. The doses for these medications, and choice of nondepolarizing neuromuscular blocking medication, were not standardized and left to the discretion of the anesthesia provider. Anesthesia was induced using non-standardized doses of the IV induction agent. Anesthesia providers were permitted to titrate the administration at their discretion to achieve loss of consciousness. All patients were monitored utilizing the same invasive and non-invasive monitoring modalities. Data were collected for the same hemodynamic parameters at the same time intervals for all patients.

The authors reported that their primary endpoint for the purpose of statistical analysis was determining the total use of vasopressor medications within the first 10 minutes after induction of anesthesia. This data was reported as either requiring vasopressor medication or not requiring vasopressor medication and between group comparisons were made using logistical regression, summarized as odds ratios with 95\% confidence intervals. The authors reported that stratification was performed to control for variations in anesthetist behavior, open versus closed-label phases, and baseline MAP. Outcome measures can be found in Appendix C-9. Based upon their findings, the authors concluded that propofol produced a 34\% greater reduction in MAP when compared with etomidate and that etomidate provided a superior hemodynamic profile to propofol.

Critical appraisal can be found in Appendix D-9. The trial focused on a clearly focused issue. The assignment of patients was randomized. All patients who were entered into the trial were accounted for at the end of the study. The study was performed in two phases. Phase I was conducted in an open-label format. Phase II was 
conducted in a closed-label format during which all clinical and study staff were blinded to the induction drug. Between group makeup was similar between groups. Withingroup makeup was skewed substantially toward male patients. The groups were treated equally insofar as they received the same medication regimen, with the exception of the treatment intervention. Dosing of the IV induction agent, as well as the other adjunct medications, varied at the discretion of the individual anesthetist. The formulation of etomidate was changed for phase II. To further blind the anesthesia provider to the treatment medication, a lipid-based emulsion formulation of etomidate was utilized, rendering it visually indistinguishable from propofol. The treatment effect was not discussed. The results can be applied to the local population. All clinically important outcomes were considered. There were no harmful or untoward events reported. The authors did comment on the safety of their approach. They reported that when both induction agents were visually indistinguishable, with a color and consistency traditionally associated with propofol, anesthetists treated both medications as though they were propofol. Since the lipid-based etomidate emulsion was not diluted so that the per milliliter concentration for the appropriate weight-based dose range was similar to propofol, this led to a more than three-fold increase in actual dose of etomidate administered during the blinded phase. The authors admitted that this method of blinding caused a deviation from practice in the blinded phase that could have put patients at risk and negatively affected outcomes; however no adverse effects were reported. 


\section{Cross-Study Analysis}

The cross-study analysis can be found in Appendix E. A single study was found (Basagan et al., 2010) comparing propofol to ketamine. All of the remaining studies (Hannam et al., 2019; Kamath et al., 2016; Kaushal et al., 2015; Mala \& Narmada, 2017; Meena et al., 2017; Pandey et al., 2012; Shivanna et al., 2015; Soleimani et al., 2017) compared propofol to etomidate and all investigated and compared the hemodynamic changes associated with the administration of each medication. Three of the studies (Kaushal et al., 2015; Meena et al., 2017; Pandey et al., 2012) investigated cortisol response to propofol and etomidate in addition to the hemodynamic changes.

Dosing of each medication was generally consistent across studies. Bolus doses of propofol were used at $2.0 \mathrm{mg} / \mathrm{kg}$ (Kaushal et al., 2015; Meena et al., 2017; Pandey et al., 2012; Soleimani et al., 2017) and $1.5 \mathrm{mg} / \mathrm{kg}$ (Kamath et al., 2016; Mala \& Narmada, 2017). An infusion of $0.5 \mathrm{mg} / \mathrm{kg} / \mathrm{min}$ of propofol was used in study 4 (Shivanna et al., 2015). Propofol was dosed at the anesthesia provider's discretion in study 9 (Hannam et al., 2019). Bolus doses of etomidate were used at $0.2 \mathrm{mg} / \mathrm{kg}$ (Kamath et al., 2016; Kaushal et al., 2015; Mala \& Narmada, 2017; Meena et al., 2017; Pandey et al., 2012) and $0.3 \mathrm{mg} / \mathrm{kg}$ (Soleimani et al., 2017). An infusion of $0.05 \mathrm{mg} / \mathrm{kg} / \mathrm{min}$ of etomidate was used in study 4 (Shivanna et al., 2015). Etomidate was dosed at the anesthesia provider's discretion in study 9 (Hannam et al., 2019). A bolus dose of ketamine was used at 0.2 $\mathrm{mg} / \mathrm{kg}$ in study 1 (Basagan et al., 2010).

The administration of propofol was generally associated with a clinically significant reduction in hemodynamic parameters after induction. The administration of propofol was associated with a reduction in SBP in all studies. Diastolic blood pressure 
was reduced in studies two, three, six and eight (Kaushal et al., 2015; Mala \& Narmada, 2017; Pandey et al., 2012; Soleimani et al., 2017). Mean arterial pressure was reduced in studies one, three, four, five, six and nine (Basagan et al., 2010; Hannam et al., 2019; Kamath et al., 2016; Kaushal et al., 2015; Mala \& Narmada, 2017; Shivanna et al., 2015). Systemic vascular resistance was reduced in studies one, two, three, and eight (Basagan et al, 2010; Kaushal et al., 2015; Pandey et al., 2012; Soleimani et al., 2017). Study six (Mala \& Narmada, 2017) reported that a greater number of patients receiving propofol required rescue administration of ephedrine when compared with etomidate. The administration of etomidate was associated with an increase in DBP, CO and CI (Mala \& Narmada, 2017), as well as HR and SBP (Soleimani et al., 2017) after intubation.

Etomidate was associated with a decreased cortisol level (Kaushal et al., 2015; Meena et al., 2017; Pandey et al., 2012), while propofol was associated with an increased cortisol level (Kaushal et al., 2015; Meena et al., 2017; Pandey et al., 2012). No statistically significant changes in hemodynamic parameters were associated with the administration of ketamine. Alterations in cortisol in response to ketamine were not studied.

\section{Creation of Decision Tree}

Based upon the information collected during the cross-study analysis, a decision tree (Figure 4, p. 55) was constructed to guide the anesthesia practitioner to the most appropriate choice of IV anesthetic for a particular patient. First, any known allergy, hypersensitivity, comorbid condition, or known genetic condition that precludes the use of a particular medication should be considered. Next, the determination must be made as to whether the patient is in a moribund state or experiencing an emergency situation. In these situations, it may be necessary for the anesthesia provider to make risk versus 
benefit judgments based upon their experience and to choose the medication that he/she believes provides the greatest likelihood of causing the least harm. Finally, decision points would be based upon the known pathophysiology of various structural heart conditions and the IV anesthetic whose hemodynamic effects profile provides the conditions best suited for the particular patient. 


\section{Induction Agent for Cardiac Surgery Decision Tree}

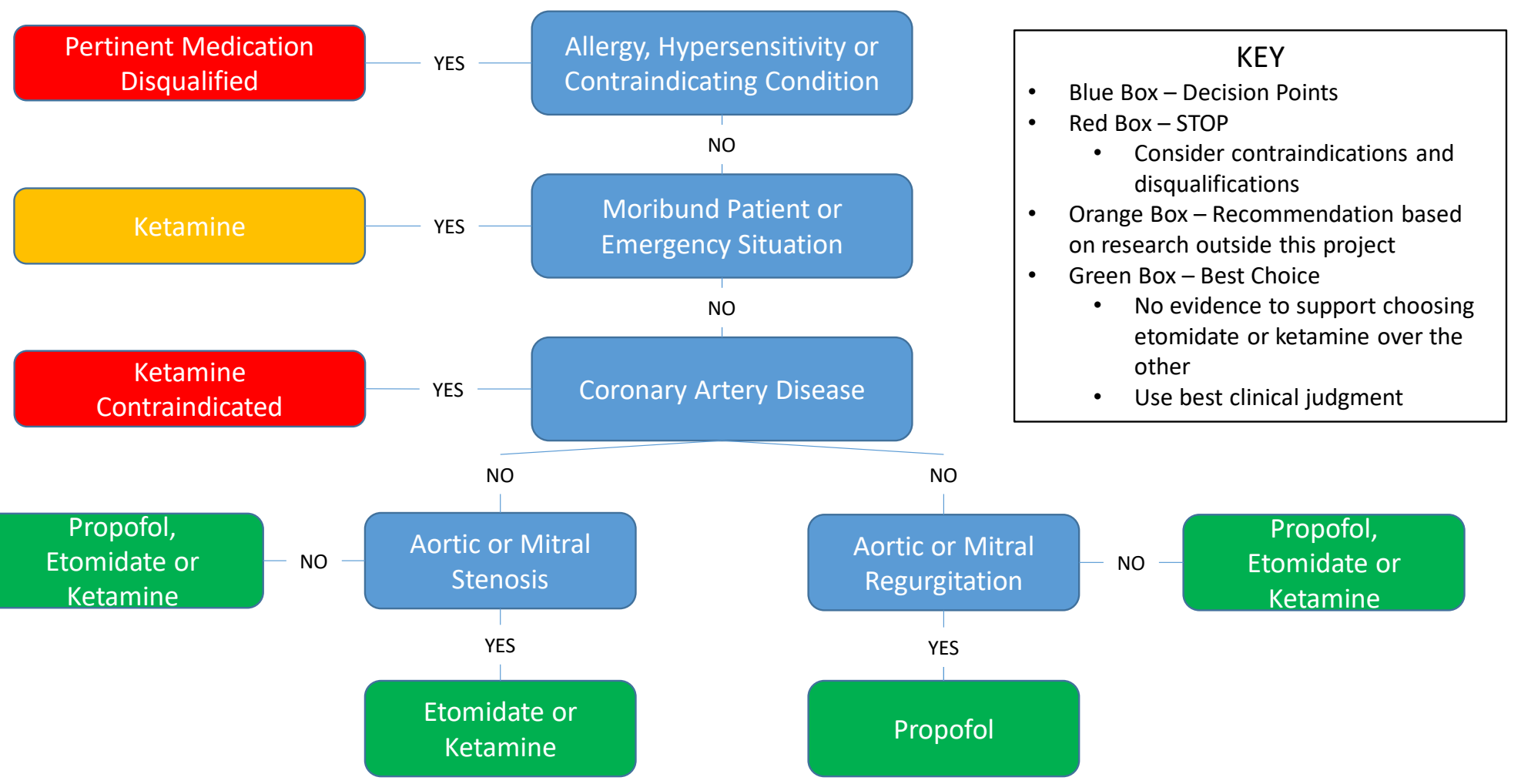

Figure 4. Decision tree 


\section{Utilization of the Decision Tree}

After a thorough review of the patient's medical record and pre-admission testing, the anesthesia provider performing the induction should perform a detailed pre-anesthesia assessment and physical exam. Based upon those findings, the anesthesia provider should refer to the decision tree to select the IV induction agent best suited for the patient's condition. It's understood that an emergency situation may preclude a thorough medical record review and/or pre-anesthesia assessment. In this instance, every attempt should be made to identify the patient's known medication allergies and pertinent medical history by any means possible. The decision tree is not a substitute for clinical judgment. The anesthesia provider should not administer any medication to a patient they feel would be harmful, regardless of the recommendation obtained from the decision tree. Personal preference, facility custom, budgetary, or other non-medical motivations are not a substitute for evidence-based practice, and should not be used as an excuse to ignore the decision tree.

The decision tree should be read from top to bottom. A key is provided for reference. Items in blue boxes are considered decision points. Items in red boxes should prompt the anesthesia provider to stop and consider eliminating the applicable medication as an option for the patient. Items in orange boxes are based upon recommendations from research outside the scope of this project. Items in green boxes are the best choice based upon the research performed during this project.

First, any medication for which a patient has a known allergy or hypersensitivity should not be used. This includes medical or genetic conditions for which administration of the particular medication could cause harmful side effects. Next, the anesthesia 
provider should consider whether or not the patient is suffering from an emergency situation rendering them hemodynamically unstable. Ketamine has been recognized as the best choice in hemodynamically unstable emergency situations by international organizations (Morris et al., 2009). Next, the anesthesia provider should consider whether or not the patient suffers from coronary artery disease. A "yes" answer eliminates ketamine as a medication choice and the anesthesia provider should continue down the decision tree without considering ketamine. A "no" answer permits the anesthesia provider to continue down the decision tree maintaining ketamine in their repertoire. Next, the anesthesia provider should consider heart valve findings from the pre-operative echocardiogram. The presence of stenotic or regurgitant valve lesions will guide the direction of travel down the decision tree where it splits into two columns. The choice of IV induction agent most appropriate for the patient is based upon the recommendation in the green box. Where multiple options are listed, clinical judgment should guide the selection. There is no evidence to support the selection of ketamine or etomidate over the other.

Next, the summary and conclusions will be discussed. 


\section{Summary and Conclusions}

Anesthesia providers have multiple IV anesthetic medications at their disposal from which to choose when selecting the agent best suited for their patients' comorbidities and the proposed surgical procedure (Nagelhout, 2014). Patients presenting for cardiac surgery are likely to bring a plethora of comorbidities affecting end organ function. These patients are high risk, as are the surgeries. It's imperative that the anesthesia provider facilitate a smooth and stable induction to protect the patient from additional physiologic compromise.

The purpose of this paper was to propose a preliminary, evidence-based decision tree to guide in the selection of an appropriate intravenous anesthetic for patients undergoing cardiac surgery. Two theoretical frameworks were utilized to guide this project. The Preferred Reporting Items for Systematic Reviews and Meta-Analysis (PRISMA) was used to guide the research process. Information Processing Theory (ITP) was implemented to guide development of the decision tree. A comprehensive literature search yielded nine RCTs meeting inclusion criteria (Appendix A). Data and outcome measures were collected from each RCT and summarized in Appendices B and C. The Critical Appraisal Skills Programme (CASP) was applied to each RCT, with results summarized in Appendix D. The cross-study analysis is detailed in appendix E. The literature review and cross-study analysis guided the creation of the decision tree. The decision tree can be found in Figure 4.

The decision tree first accounts for allergies and hypersensitivities, followed by conditions for which the administration of a particular IV anesthetic could cause severe or life-threatening consequences notwithstanding the hemodynamic changes. For example, etomidate is contraindicated in patients with porphyrrias (Nagelhout, 2014). 
Emergency situations must be handled differently than elective cases. Ketamine is generally recognized as a vital medication during emergency situations (Morris et al., 2009). The cross-study analysis guided the development of the subsequent steps in the decision tree.

Principal findings of the cross-study analysis include the association of a clinically significant reduction in several hemodynamic parameters with propofol when compared with ketamine and etomidate. Ketamine was associated with superior maintenance of MAP and SVR. Across applicable studies, etomidate was associated with a more stable hemodynamic profile than propofol. When comparing data collection points across studies comparing propofol to etomidate, results were relatively consistent, depending on hemodynamic parameters measured, within-procedure collection intervals, and conclusions reported. Generally, patients receiving propofol experienced a clinically significant decline in blood pressure (SBP, DBP and/or MAP) after induction when compared with etomidate. Two studies (Kamath et al., 2016; Meena et al., 2017) reported an increased HR and some blood pressure parameter after intubation in patients receiving etomidate. This is consistent with etomidate's lack of sympathetic blunting and customary patient response to intubation. Kamath et al (2016) also reported increased $\mathrm{CO}$ and $\mathrm{CI}$ after intubation when etomidate was used, which is consistent with the physiologic changes seen with a sympathetic discharge during intubation. Two studies (Kaushal et al., 2015; Soleimani et al., 2017) reported a significant decrease in SVR with etomidate, although to a lesser degree than propofol. In studies utilizing cortisol response as an outcome measure, etomidate was generally associated with a decrease in cortisol 
levels while propofol was associated with an increase. Long-term effects of cortisol response were outside the scope of these studies.

Propofol, etomidate, and ketamine each have their place in the care of cardiac surgery patients. Anesthesia providers can utilize their understanding of the pharmacology of IV anesthetics and the pathophysiology of various structural heart diseases to guide their decision-making. In patients with conditions having hemodynamic needs at odds with each other (i.e. CAD and aortic stenosis), it may be necessary to choose "the lesser of two evils" and select the medication that will generate the more easily addressed side effects. In general, patients presenting with conditions for which blood pressure and SVR must be maintained, such as patients with stenotic valve pathologies, would benefit from a medication that preserves each, such as etomidate or ketamine. Ketamine should be avoided in patients for which an increased HR and myocardial oxygen demand would be detrimental. Myocardial ischemia during induction could ultimately lead to additional myocardial damage. Etomidate, or carefully titrated propofol, would provide the safest induction in these patients. Propofol's best use will be in patients for which a decrease in SVR is desirable, such as in regurgitant valve pathologies. Ketamine's best use may be in the case of emergency procedures or in patients where preservation of compensatory mechanisms is paramount. Its bronchodilatory effects may also benefit patients with coexisting severe reactive airway disease.

Limitations were identified at various points throughout the completion of this project. One lone study meeting the inclusion criteria was found comparing propofol with ketamine. The findings in this study are consistent with what would be expected 
based on the pharmacology of each medication and the known physiologic responses. No studies were located comparing etomidate with ketamine during cardiac surgery. This likely dictates that any decision regarding medication selection between the two be dependent upon the known indications and contraindications to each medication rather than direct evidence demonstrating the benefit of one over the other. Dosing of medications was not consistent across all studies. Differing bolus doses were seen across studies and one study employed infusions rather than boluses. Another study permitted the anesthesia provider to administer the assigned medication by the method and dose of their choosing. This interferes with the ability to demonstrate the safest dose/administration procedure yet does establish that the patients' responses are reasonably consistent across protocols.

The process used to develop this project also presented limitations. The nature of modern evidence-based practice favors the utilization of the most current information. Limiting the inclusion criteria to studies performed in the previous ten-year period increased the likelihood that data further supporting or disputing the conclusions were omitted. Excluding research published in languages other than English may have had the same effect. The researcher's lack of experience conducting projects of this nature may also have limited the quality of the research and the veracity of its findings or recommendations.

Next, the recommendations and implications for advanced nursing practice will be discussed. 


\section{Recommendations and Implications for Advanced Nursing Practice}

Advanced Practice Registered Nurses (APRN) are perfectly positioned as leaders in the healthcare system. In addition to their extensive education and experience at the bedside in the $\mathrm{RN}$ role, APRNs are trained to provide comprehensive and compassionate care within their area of expertise. Evidence-based practice is the foundation of nursing education at all levels. Nurses are trained to seek out the best available evidence, evaluate that evidence, and implement their findings into clinical practice so as to provide their patients the best possible care. The cumulative benefits of APRN experience, education and capability uniquely qualify them to meet the complex needs of their patients.

Certified Registered Nurse Anesthetists in particular are in a position to lead innovation practice improvements. The rigor of CRNA education, coupled with its strong foundation in the sciences, augments the evidence-based, patient-centered nursing care all CRNAs learned to provide at the bedside. Certified Registered Nurse Anesthetists are often the sole anesthesia provider, especially in rural areas where resources are limited. As experts in the provision of all modalities of anesthesia care in all settings, CRNAs are sought after for their expertise and leadership skills. They are in a unique position to assume a leadership role and champion practice improvements through the implementation of evidence-based interventions.

The utilization of two theoretical frameworks played a pivotal role in realizing the benefits of this project. Most research studies focus on answering a particular question or set of questions. These studies may or may not discuss the manner in which practitioners could implement those answers into generalized practice. The combination of the two frameworks used (PRISMA and IPT) not only assisted in finding and processing the 
available evidence on the research topic, but also served as the foundation for the subsequent steps necessary to translate the evidence into practice. In order for new evidence to extend beyond the esoteric and abstract, we must be able to demonstrate the mechanism by which it can be used for the betterment of patients. Understanding the decision-making process, especially by healthcare practitioners, is vital to establishing the basis for moving research findings from the classroom to the bedside. It would be beneficial for nursing educators and change leaders in the healthcare industry to expand their research processes to include decision-making theories as a compulsory component.

This type of research supports culturally competent care to diverse populations and works toward ensuring ethical practice by all caregivers. Each and every patient deserves the highest level of care, backed by the latest evidence, to guide their treatment and see them through to the best possible outcome. Sound decision-making practices based on solid evidence, distilled through an interdisciplinary team of expert clinicians can achieve those goals. This project lends some insight into how APRNs in general, and CRNAs in particular, can use research to enhance patient care. They are uniquely prepared to lead these efforts.

Certified registered nurse anesthetists (CRNAs) in particular are positioned to lead a team of caregivers from multiple disciplines to see the patient through the surgical experience. Certified Registered Nurse Anesthetists are educated to practice independently while providing all types of anesthesia to all patient populations. Decision trees such as the one developed in this project, as well as other decision-making aids, will complement the education, experience, and critical-thinking expertise of CRNAs as they work to provide the best possible care to their patients. Nurse anesthesia educational 
programs are the ideal setting to nurture the thought processes and leadership skills needed to increase the ubiquity of evidence-based guidelines and decision trees. Beginning in 2025, all graduates of nurse anesthesia educational programs will be required to earn a Doctor of Nursing Practice (DNP) for entry into practice (Madsen Gombkoto et al., 2014). Many programs have already transitioned to a DNP curriculum. With the DNP program requirement of the completion of a practice improvement project, all new CRNAs will launch their career with experience in designing and implementing evidence-based practice improvements. The integration of decision-making processes should be a compulsory component of these projects.

Much work remains to be done to overcome dated attitudes and individual comfort zones. The first step would be to recognize the subject areas with the greatest discrepancy between current behavior and best practices. Further research is needed to identify topic areas with the greatest inconsistencies to guide the prioritization of practice improvement efforts. Another area of future research could involve revisiting past evidence-based implementation attempts which failed to produce the desired results. Incorporating research related to decision-making in healthcare could bridge the gap between the practice improvement and its successful implementation with optimal results.

Decision trees such as the one developed during this project can improve practice to coincide with the most current research on a particular topic and support consistency within an organization. This effort requires collaboration among all stakeholders and across multiple disciplines. Some changes may necessitate organizational policy modifications, or perhaps legislative action. Focused, professional leadership is 
necessary to navigate the process. Certified Registered Nurse Anesthetists are the ideal expert providers to utilize their education, experience and position as respected APRNs to champion these efforts. 


\section{References}

American Association of Nurse Anesthetists. (2019). Standards of Nurse Anesthesia Practice. Retrieved from https://www.aana.com/docs/default-source/practiceaana-com-web-documents-(all)/standards-for-nurse-anesthesiapractice.pdf?sfvrsn $=\mathrm{e} 00049 \mathrm{~b} 1 \_2$

American Society of Anesthesiologists. (2014). Continuum of depth of sedation:

Definition of general anesthesia and levels of sedation/analgesia. Retrieved from https://www.asahq.org/ /media/Sites/ASAHQ/Files/Public/Resources/standardsguidelines/continuum-of-depth-of-sedation-definition-of-general-anesthesia-andlevels-of-sedation-analgesia.pdf

Bamber, J. H., \& Evans, S. A. (2016). The value of decision tree analysis in planning anaesthetic care in obstetrics. International Journal of Obstetric Anesthesia, 27, 55-61. https://doi.org/10.1016/j.ijoa.2016.02.007

Banning, M. (2008). A review of clinical decision making: Models and current research. Journal of Clinical Nursing, 17(2), 187-195. https://doi.org/10.1111/j.13652702.2006.01791.x

Basagan-Mogol, E., Goren, S., Korfali, G., Turker, G., \& Kaya, F. N. (2010). Induction of anesthesia in coronary artery bypass graft surgery: The hemodynamic and analgesic effects of ketamine. Clinics, 65(2), 133-138.

https://doi.org/10.1590/S1807-59322010000200003

Contrera, M. A., Patterson, M., \& Cushing, M. (2014). Anesthesia for cardiac surgery. In J. J. Nagelhout \& K. L. Plaus (Eds.), Nurse anesthesia (5th ed., pp. 510-560). St. Louis, MO: Elsevier. 
Cozmuta, R., Merkel, P. A., Wahl, E., \& Fraenkel, L. (2014). Variability of the impact of adverse events on physicians' decision making. BMC Medical Informatics and Decision Making, 14(86). https://doi.org/

Dean, C., \& Chapman, E. (2018). Induction of anesthesia. Anaesthesia and Intensive Care Medicine, 19(8), 383-388. https://doi.org/10.1016/j.mpaic.2018.05.008

Eichhorn, J. H. (2013). Review article: Practical current issues in perioperative patient safety. Canadian Journal of Anesthesia, 60, 111-118. https://doi.org/ $10.1007 / \mathrm{s} 12630-012-9852-\mathrm{Z}$

Erdoes, G., Basciani, R. M., \& Eberle, B. (2014). Etomidate - a review of robust evidence for its use in various clinical scenarios. Acta Anaesthesiologica Scandinavica, 58, 380-389. https://doi.org/10.1111/aas. 12289

Forman, S. A. (2011). Clinical and molecular pharmacology of etomidate. Anesthesiology, 114(3), 695-707. https://doi.org/10.1097/ALN.0b013e3181ff72b5

Hannam, J. A., Mitchell, S. J., Cumin, D., Frampton, C., Merry, A. F., Moore, M. R., \& Kruger, C. J. (2019). Haemodynamic profiles of etomidate vs propofol for induction of anaesthesia: A randomised controlled trial in patients undergoing cardiac surgery. British Journal of Anaesthesia, 122(2), 198-205. https://doi.org/10.1016/j.bja.2018.09.027

Harper, N. J. (2016). Propofol and food allergy. British Journal of Anesthesia, 116(1), 11-13. https://doi.org/10.1093/bja/aev401

Herrera, A. (2018). Valvular heart disease. In R. L. Hines \& K. E. Marschall (Eds.), Stoelting's anesthesia and co-existing disease (7th ed. (pp. 107-128). Philadelphia, PA: Elsevier. 
Hibbert, B., Nathan, H. J., Simard, T., \& O’Brien, E. R. (2018). Coronary physiology and atherosclerosis. In J. A. Kaplan, B. Cronin, \& T. Maus (Eds.), Kaplan's essentials of cardiac anesthesia for cardiac surgery (2nd ed. (pp. 94-111). Philadelphia, PA: Elsevier.

Hudetz, J. A., Iqbal, Z., Gandhi, D., Patterson, K. M., Byrne, A. J., Hudetz, A. G., ... Warltier, D. C. (2009). Ketamine attenuates post-operative cognitive dysfunction after cardiac surgery. Acta Anaesthesiologica Scandanavica, 53, 864-872. https://doi.org/10.1111/j.1399-6576.2009.01978.x

Information Processing Model [Image]. (n.d.). Retrieved from https://slideplayer.com/slide/10762208/38/images/4/A+Model+of+Information+P rocessing.jpg

James, M. F., \& Hift, R. J. (2000). Porphyrias. British Journal of Anaesthesia, 85(1), 143-153. https://doi.org/10.1093/bja/85.1.143

Joseph, G. M., \& Patel, V. L. (1990). Domain knowledge and hypothesis generation in diagnostic reasoning. Medical Decision Making, 10(1), 31-46. https://doi.org/10.1177/0272989X9001000107

Kamath, M. R., Kamath, S., \& Patla, K. P. (2016). Propofol or etomidate: Does it genuinely matter for induction in cardiac surgical procedures? Indian Journal of Clinical Anesthesia, 3(4), 551-555. https://doi.org/10.18231/23944994.2016.0012

Kaushal, R. P., Vatal, A., \& Pathak, R. (2015). Effect of etomidate and propofol induction on hemodynamic and endocrine response in patients undergoing coronary artery bypass grafting/mitral valve and aortic valve replacement surgery 
on cardiopulmonary bypass. Annals of Cardiac Anesthesia, 18(2), 172-178. https://doi.org/10.4103/0971-9784.154470

Khan, K. S., Hayes, I., \& Buggy, D. J. (2014a). Pharmacology of anaesthetic agents II: Inhalation anaesthetic agents. Continuing Education in Anaesthesia, Critical Care \& Pain, 14(3), 106-111. https://doi.org/10.1093/bjaceaccp/mkt038

Khan, K. S., Hayes, I., \& Buggy, D. J. (2014b). Pharmacology of anesthetic agents I: Intravenous anesthetic agents. Continuing Education in Anaesthesia Critical Care \& Pain, 14(3), 100-105. https://doi.org/10.1093/bjaceaccp/mkt039

Kossick, M. A. (2014). Inhalation anesthetics. In J. J. Nagelhout \& K. L. Plaus (Eds.), Nurse anesthesia (5th ed. (pp. 85-103). St. Louis, MO: Elsevier Saunders.

Lee, A., Joynt, G. M., Ho, A. M., Keitz, S., McGinn, T., \& Wyer, P. C. (2009). Tips for teachers of evidence-based medicine: Making sense of decision analysis using a decision tree. Journal of General Internal Medicine, 24(5), 642-648. https://doi.org/10.1007/s11606-009-0918-8

Liberati, A., Altman, D. G., Tetzlaff, J., Mulrow, C., Getzsche, P. C., Ioannidis, J. P., ... Moher, D. (2009). The PRISMA statement for reporting systematic reviews and meta-analyses of studies that evaluate health care interventions: Explanation and Elaboration. PLoS Med, 6(7), 1-28. https://doi.org/10.1371/journal.pmed.1000100 Madsen Gombkoto, R. L., Walker, J. R., Horton, B. J., Martin-Sheridan, D., Yablonsky, M. J., \& Gerbasi, F. R. (2014). Council on Accreditation of Nurse Anesthesia Educational Programs adopts standards for the practice doctorate and postgraduate CRNA fellowships. AANA Journal, 82(3), 177-183. Retrieved from https://www.aana.com/publications/aana-journal 
Mala, R., \& Narmada, S. (2017). Prospective randomised study comparing the haemodynamic and endocrine response to induction with etomidate and propofol in patients undergoing cardiac surgery on cardiopulmonary bypass. Indian Journal of Applied Research, 7(10), 145-146. Retrieved from https://www.worldwidejournals.com/indian-journal-of-applied-research(IJAR)/fileview/October_2017_1506777489_54.pdf

Marland, S., Ellerton, J., Andolfatto, G., Strapazzon, G., Thomassen, O., Brandner, B., ... Paal, P. (2013). Ketamine: Use in anesthesia. CNS Neuroscience \& Therapeutics, 19, 381-389. https://doi.org/10.1111/cns.12072

Meena, R., Sharma, R. S., Ranawat, P., Saiyed, A., \& Verma, I. (2017). Comparison of hemodynamic and serum cortisol levels in response to anesthetic induction with etomidate or propofol in patients undergoing CABG surgery. Indian Journal of Clinical Anaesthesia, 4(3), 345-351. https://doi.org/10.18231/23944994.2017.0071

Mittnacht, A. J., London, M. J., Puskas, J. D., \& Kaplan, J. A. (2018). Anesthesia for myocardial revascularization. In J. A. Kaplan, B. Cronin, \& T. Maus (Eds.), Kaplan's essentials of cardiac anesthesia for cardiac surgery (2nd ed. (pp. 322351). Philadelphia, PA: Elsevier.

Moher, D., Liberati, A., Tetzlaff, J., Martin, D. C., \& The PRISMA Group (2009). Preferred reporting systems for systematic reviews and meta-analyses: The PRISMA statement. PLoS Med, 6(7), 1-6. https://doi.org/10.1371/journal.pmed.1000097 
Morris, C., Perris, A., Klein, J., \& Mahoney, P. (2009). Anaesthesia in haemodynamically compromised emergency patients: Does ketamine represent the best choice of induction agent? Anaesthesia, 64, 532-539. https://doi.org/10.1111/j.1365-2044.2008.05835.x

Munst, L., Schlapfer, M., \& Biro, P. (2018). Anaesthetic drug choices of senior anaesthetists: An observational analysis of medication habits in a tertiary hospital. Turkish Journal of Anesthesia \& Reanimation, 46(5), 348-353. https://doi.org/10.5152/TJAR.2018.00236

Nagelhout, J. J. (2014). Intravenous induction agents. In J. J. Nagelhout \& K. L. Plaus (Eds.), Nurse anesthesia (5th ed. (pp. 104-124). St. Louis, MO: Elsevier Saunders.

Pandey, A. K., Makhija, N., Chauhan, S., Das, S., Kiran, U., Bisoi, A. K., \& Lakshmy, R. (2012). The effects of etomidate and propofol induction on hemodynamic and endocrine response in patients undergoing coronary artery bypass graft surgery on cardiopulmonary bypass. World Journal of Cardiovascular Surgery, 2(3), 48-53. https://doi.org/10.4236/wjcs.2012.23011

Paul, A., \& Des, S. (2017). Valvular heart disease and anaesthesia. Indian Journal of Anesthesia, 61(9), 721-727. https://doi.org/0.4103/ija.IJA_378_17

Rathmell, J. P., \& Rosow, C. E. (2015). Intravenous sedatives and hypnotics. In P. Flood, J. P. Rathmell, \& S. Shafer (Eds.), Stoelting's pharmacology \& physiology in anesthetic practice (5th ed. (pp. 160-203). Philadelphia, PA: Wolters Kluwer Health. 
Rotter, T., Kisman, L., James, E., Machotta, A., Willis, J., Snow, P., \& Kugler, J. (2012). The effect of clinical pathways on professional practice, patient outcomes, length of stay, and hospital costs: Cochrane systematic review and meta-analysis. Cochrane Database of Systematic Reviews, 35(1), 3-27. https://doi.org/10.1177/0163278711407313

Sahinovic, M. M., Struys, M. M., \& Absalom, A. R. (2018). Clinical pharmacokinetics and pharmacodynamics of propofol. Clinical Pharmacokinetics, 57(12), 15391558. https://doi.org/10.1007/s40262-018-0672-3

Shivanna, S., Priye, S., Jagannath, S., Kadli, C., Mayuri, Vikas, ... Reddy, D. (2015). A comparative study of haemodynamic effects of propofol and etomidate as an induction agent in coronary artery surgery. Journal of Evolution of Medical and Dental Sciences, 4(1), 598-607. https://doi.org/10.14260/jemds/2015/88

Singh, J. (2013). Critical appraisal skills programme. Journal of Pharmacology and Pharmacotherapeutics, 4(1), 76-77. https://doi.org/10.4103/0976-500X.107697

Soleimani, A., Heidari, N., Habibi, M. R., Kiabi, F. H., Khademloo, M., Zeydi, A. E., \& Sohrabi, F. B. (2017). Comparing hemodynamic responses to diazepam, propofol and etomidate during anesthesia induction in patients with left ventricular dysfunction undergoing coronary artery bypass graft surgery: A double-blind, randomized clinical trial. Medical Archives, 71(3), 198-203.

https://doi.org/10.5455/medarh.2017.71.198-203

Stiegler, M. P., \& Tung, A. (2014). Cognitive processes in anesthesiology. Anesthesiology, 120(1), 204-217. https://doi.org/10.1097/ALN.0000000000000073 


\section{Appendix A}

\section{PRISMA 2009 Flow Diagram}

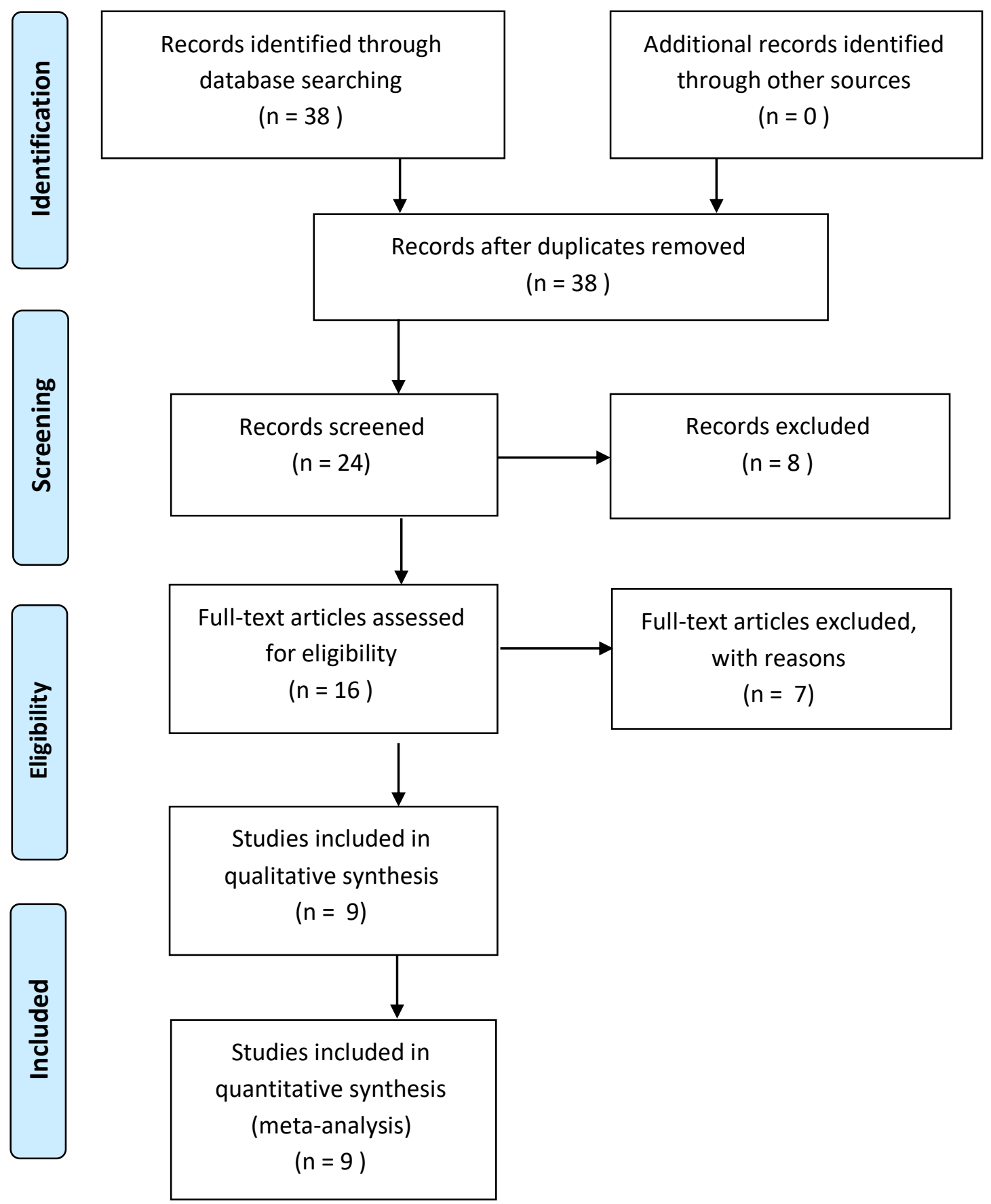

From: Moher D, Liberati A, Tetzlaff J, Altman DG, The PRISMA Group (2009). Preferred Reporting /tems for Systematic Reviews and Meta-Analyses: The PRISMA Statement. PLoS Med 6(7): e1000097. doi:10.1371/journal.pmed1000097 


\section{Appendix B}

\section{Table B-1}

\begin{tabular}{|c|c|c|c|c|c|}
\hline \multicolumn{6}{|c|}{$\begin{array}{l}\text { Basagan-Mogol, E., Goren, S., Korfali, G., Turker, G., \& Kaya, F. N. (2010). Induction of anesthesia in coronary artery bypass graft } \\
\text { surgery: The hemodynamic and analgesic effects of ketamine. Clinics, 65(2), 133-138. https://doi.org/10.1590/S1807 } \\
59322010000200003\end{array}$} \\
\hline Research Question & Project Design & Site, Sample & Method & Results & Limitations \\
\hline $\begin{array}{l}\text { To evaluate the } \\
\text { hemodynamic and } \\
\text { analgesic effects of } \\
\text { ketamine by comparing } \\
\text { it with propofol starting } \\
\text { at the induction of } \\
\text { anesthesia until the end } \\
\text { of sternotomy in } \\
\text { patients undergoing } \\
\text { coronary artery bypass } \\
\text { grafting surgery }\end{array}$ & $\begin{array}{l}\text { Randomized controlled } \\
\text { trial with two groups, } \\
\text { each comprised of } 15 \\
\text { patients, undergoing } \\
\text { CABG } \\
\text { Group K ( } \mathrm{n}=15) \text { : } \\
\text { Received ketamine as } \\
\text { IV induction agent } \\
\text { Group } \mathrm{P}(\mathrm{n}=15) \text { : } \\
\text { Received propofol as } \\
\text { IV induction agent }\end{array}$ & $\begin{array}{l}\text { Thirty patients, ages } \\
35-75 \text {, ASA class III or } \\
\text { IV, scheduled for } \\
\text { elective CABG } \\
\text { All patients had good } \\
\text { left ventricular function } \\
\text { (defined as LVEF }> \\
40 \% \text { and LVEDP }<15 \\
\text { mmHg). } \\
\text { Excluded patients: } \\
\text { valve disease, diabetes, } \\
\text { severe renal or hepatic } \\
\text { dysfunction, drug or } \\
\text { alcohol abuse and those } \\
\text { presenting for a second } \\
\text { or subsequent CABG } \\
\text { procedure }\end{array}$ & $\begin{array}{l}\text { All patients received } \\
\text { similar weight-based } \\
\text { doses of morphine, } \\
\text { midazolam, fentanyl, } \\
\text { and rocuronium. } \\
\text { Group K patients } \\
\text { received } 2 \mathrm{mg} / \mathrm{kg} \\
\text { ketamine. } \\
\text { Group P patients } \\
\text { received } 0.5 \mathrm{mg} / \mathrm{kg} \\
\text { propofol. } \\
\text { Hemodynamic } \\
\text { measurements: pre- } \\
\text { induction, one minute } \\
\text { after induction, one, } \\
\text { three and ten minutes } \\
\text { after intubation, one } \\
\text { minute after incision, } \\
\text { and one minute after } \\
\text { sternotomy }\end{array}$ & $\begin{array}{l}\text { One minute after } \\
\text { induction, significant } \\
\text { decreases in MAP and } \\
\text { SVR one minute after } \\
\text { induction in Group P (p } \\
<0.01 \text { ) } \\
\text { No significant changes } \\
\text { in HR, PAP, PCWP, } \\
\text { PVR, SV, LVSWI, or } \\
\text { RVSWI between } \\
\text { groups } \\
\text { No significant changes } \\
\text { in ST segment } \\
\text { deviation from baseline } \\
\text { between groups }\end{array}$ & $\begin{array}{l}\text { Lack of bispectral index } \\
\text { (BIS) monitoring }\end{array}$ \\
\hline
\end{tabular}


Note: IV-intravenous, CABG - coronary artery bypass grafting, ASA-American Association of Anesthesiologists, LVEF-left ventricular ejection fraction, LVEDP=left ventricular end diastolic pressure, MAP-mean arterial pressure, SVR-systemic vascular resistance, HR-heart rate, PAP-pulmonary artery pressure, PCWP-pulmonary artery wedge pressure, PVR-pulmonary vascular resistance, SV-stroke volume, LVSWI-left ventricular stroke work index, RVSWI-right ventricular stroke work index 
Table B-2

Pandey, A. K., Makhija, N., Chauhan, S., Das, S., Kiran, U., Bisoi, A. K., \& Lakshmy, R. (2012). The effects of etomidate and propofol induction on hemodynamic and endocrine response in patients undergoing coronary artery bypass graft surgery on cardiopulmonary bypass. World Journal of Cardiovascular Surgery, 2(3), 48-53. https://doi.org/10.4236/wjcs.2012.2301

\begin{tabular}{|c|c|c|c|c|c|}
\hline Research Question & Project Design & Site, Sample & Method & Results & Limitations \\
\hline $\begin{array}{l}\text { To compare the effects } \\
\text { of propofol and } \\
\text { etomidate induction on } \\
\text { hemodynamic } \\
\text { parameters and serum } \\
\text { cortisol levels in } \\
\text { patients with normal } \\
\text { left ventricular function } \\
\text { undergoing elective } \\
\text { CABG on CPB }\end{array}$ & $\begin{array}{l}\text { Randomized controlled } \\
\text { trial of } 100 \text { consecutive } \\
\text { patients, with two } \\
\text { groups, each comprised } \\
\text { of } 50 \text { patients, } \\
\text { undergoing CABG with } \\
\text { CPB } \\
\text { Group } E \text { ( } n=50) \text { : } \\
\text { Received etomidate as } \\
\text { IV induction agent } \\
\text { Group P ( } n=50) \text { : } \\
\text { Received propofol as } \\
\text { IV induction agent }\end{array}$ & $\begin{array}{l}\text { Study conducted at the } \\
\text { Cardiothoracic Centre, } \\
\text { All India Institute of } \\
\text { Medical Sciences, New } \\
\text { Delhi, India } \\
\text { One hundred } \\
\text { consecutive patients, } \\
\text { ASA class II or III, } \\
\text { scheduled for elective } \\
\text { CABG } \\
\text { All patients had } \\
\text { "normal LV function". } \\
\text { "Normal" is not defined } \\
\text { Excluded: pre-existing } \\
\text { arrhythmias, CHF, } \\
\text { renal dysfunction } \\
\text { (creatinine > } 2 \text { mg/dl), } \\
\text { bleeding/coagulopathic } \\
\text { conditions, receiving } \\
\text { steroid therapy, } \\
\text { mechanically ventilated } \\
\text { preoperatively, or } \\
\text { undergoing an } \\
\text { emergency operation }\end{array}$ & $\begin{array}{l}\text { All patients received } \\
\text { similar weight-based } \\
\text { doses of morphine, } \\
\text { phenergan, midazolam, } \\
\text { fentanyl, and } \\
\text { rocuronium } \\
\\
\text { Group E patients } \\
\text { received } 0.2 \mathrm{mg} / \mathrm{kg} \\
\text { etomidate } \\
\text { Group P patients } \\
\text { received } 2.0 \mathrm{mg} / \mathrm{kg} \\
\text { propofol } \\
\text { Hemodynamic } \\
\text { measurements taken } \\
\text { pre-induction, and } \\
\text { again five minutes post- } \\
\text { intubation } \\
\text { Serum cortisol levels } \\
\text { measured pre-induction, } \\
\text { after termination of } \\
\text { CPB, and } 24 \text { hours } \\
\text { post-op }\end{array}$ & 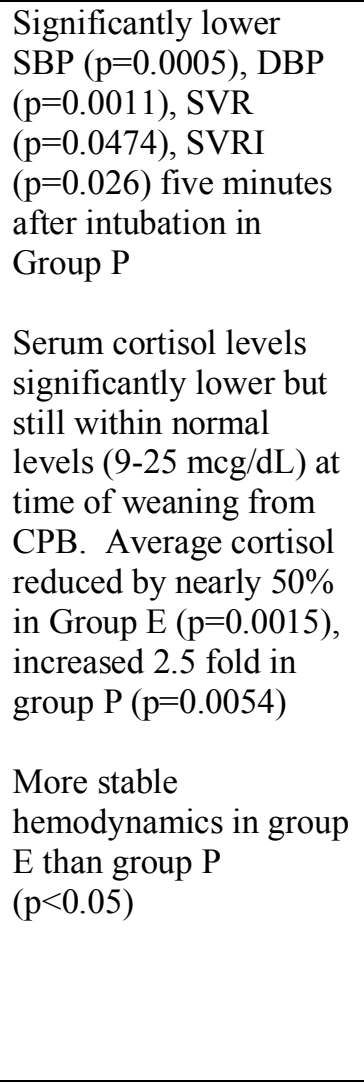 & $\begin{array}{l}\text { Small sample size, } \\
\text { same site, same surgical } \\
\text { team, only patients with } \\
\text { normal LV function }\end{array}$ \\
\hline
\end{tabular}


Note: IV-intravenous, CABG - coronary artery bypass grafting, CPB-cardiopulmonary bypass, ASA-American Association of Anesthesiologists, CHFcongestive heart failure, LV- left ventricular, SBP-systolic blood pressure, DBP-diastolic blood pressure pressure, SVR-systemic vascular resistance, SVRIsystemic vascular resistance index 
Table B-3

Kaushal, R. P., Vatal, A., \& Pathak, R. (2015). Effect of etomidate and propofol induction on hemodynamic and endocrine response in patients undergoing coronary artery bypass grafting/mitral valve and aortic valve replacement surgery on cardiopulmonary bypass. Annals of Cardiac Anesthesia, 18(2), 172-178. https://doi.org/10.4103/0971-9784.154470

\begin{tabular}{|c|c|c|c|c|c|}
\hline Purpose & Project Design & Site, Sample & Method & Results & Limitations \\
\hline $\begin{array}{l}\text { To compare induction } \\
\text { with etomidate and } \\
\text { propofol in cardiac } \\
\text { surgeries }\end{array}$ & $\begin{array}{l}\text { Prospective, } \\
\text { randomized study of } 60 \\
\text { patients randomly } \\
\text { divided into two } \\
\text { groups, each comprised } \\
\text { of } 30 \text { patients, } \\
\text { undergoing CABG, } \\
\text { MVR, AVR on CPB } \\
\text { Group I (n=30): } \\
\text { Received propofol as } \\
\text { IV induction agent } \\
\text { Group II (n=30): } \\
\text { Received etomidate as } \\
\text { IV induction agent } \\
\text { Randomization } \\
\text { performed by opening a } \\
\text { sealed envelope just } \\
\text { before entering } \\
\text { operating theater }\end{array}$ & $\begin{array}{l}\text { Study site not provided } \\
\text { Sixty patients, ages } 20 \text { - } \\
60 \text {, weighing } 40-70 \mathrm{~kg} \text {, } \\
\text { ASA class II or III, } \\
\text { scheduled for elective } \\
\text { CABG, AVR, or MVR } \\
\text { on CPB } \\
\text { Excluded: pre-existing } \\
\text { CHF, renal dysfunction } \\
\text { (creatinine }>2 \text { mg/dl), } \\
\text { receiving long term } \\
\text { steroid therapy, } \\
\text { mechanically ventilated } \\
\text { preoperatively, with } \\
\text { known adrenal or } \\
\text { endocrine dysfunction, } \\
\text { or undergoing an } \\
\text { emergency operation }\end{array}$ & $\begin{array}{l}\text { All patients: identical } \\
\text { doses of glycopyrrolate, } \\
\text { midazolam, ranitidine, } \\
\text { and ondansetron, same } \\
\text { weight-based dose of } \\
\text { fentanyl } \\
\text { Group I: } 2 \mathrm{mg} / \mathrm{kg} \\
\text { propofol } \\
\text { Group II:0.2 mg/kg } \\
\text { etomidate } \\
\text { Hemodynamic } \\
\text { measurements taken } \\
\text { pre-induction, after } \\
\text { induction, after } \\
\text { intubation, and five } \\
\text { minutes post intubation } \\
\text { Serum cortisol levels } \\
\text { measured pre-induction, } \\
\text { during CPB, after } \\
\text { termination of CPB, } \\
\text { and } 24 \text { hours post-op }\end{array}$ & $\begin{array}{l}\text { Significantly decreases } \\
\text { in SBP ( }<<0.001) \text {, DBP } \\
(\mathrm{p}=0.007) \text {, MAP } \\
(\mathrm{p}<0.001) \text { in Group I. } \\
\text { Significant decrease in } \\
\text { SVR in both groups. } \\
\text { Five minutes post } \\
\text { induction ( } \mathrm{p}<0.001 \text { ) } \\
\text { Significant decrease in } \\
\text { serum cortisol } \\
\text { (approximately } 50 \%) \\
\text { during and post CPB in } \\
\text { etomidate group while } \\
\text { almost doubling in } \\
\text { propofol group. Levels } \\
\text { returned to baseline } \\
\text { after } 24 \text { hours in both } \\
\text { groups ( }<<0.001 \text { ) }\end{array}$ & Not discussed \\
\hline
\end{tabular}


Note: IV-intravenous, CABG - coronary artery bypass grafting, MVR-mitral valve replacement, AVR-aortic valve replacement, CPB-cardiopulmonary bypass, ASA-American Association of Anesthesiologists, CHF-congestive heart failure, SBP-systolic blood pressure, DBP-diastolic blood pressure pressure, MAP-mean arterial pressure, CO-cardiac output, CI-cardiac index, SVR-systemic vascular resistance 
Table B-4

Shivanna, S., Priye, S., Jagannath, S., Kadli, C., Mayuri, M., Vikas, V., ... Reddy, D. (2015). A comparative study of haemodynamic effects of propofol and etomidate as an induction agent in coronary artery surgery. Journal of Evolution of Medical and Dental Sciences, 4(1), 2278-4748. https://doi.org/10.14260/jemds/2015/88

\begin{tabular}{|c|c|c|c|c|c|}
\hline Purpose & Project Design & Site, Sample & Method & Results & Limitations \\
\hline $\begin{array}{l}\text { To evaluate the } \\
\text { hemodynamic effects of } \\
\text { etomidate in } \\
\text { comparison to that of } \\
\text { propofol during } \\
\text { induction of general } \\
\text { anesthesia }\end{array}$ & $\begin{array}{l}\text { Prospective, } \\
\text { randomized, double } \\
\text { blind comparative study } \\
40 \text { consecutive patients } \\
\text { randomly divided into } \\
\text { two groups, each } \\
\text { comprised of } 20 \\
\text { patients, undergoing } \\
\text { CABG with CPB } \\
\text { Group P ( } \mathrm{n}=20 \text { ): } \\
\text { Received propofol as } \\
\text { IV induction agent } \\
\text { Group E (n=20): } \\
\text { Received etomidate as } \\
\text { IV induction agent }\end{array}$ & $\begin{array}{l}\text { Site: Vydehi Institute of } \\
\text { Medical Sciences and } \\
\text { Research Centre, } \\
\text { Bengaluru, India } \\
\text { Forty consecutive adult } \\
\text { patients with normal } \\
\text { LV function, ages } 35- \\
65 \text {, weighing } 40-70 \mathrm{~kg} \text {, } \\
\text { ASA class I or II, } \\
\text { scheduled for elective } \\
\text { CABG with CPB } \\
\text { Excluded: LVEF }<50 \% \text {, } \\
\text { pre-existing } \\
\text { arrhythmias, CHF, } \\
\text { coexisting cardiac } \\
\text { diseases, } \\
\text { bleeding/coagulation } \\
\text { abnormalities, renal } \\
\text { dysfunction (creatinine } \\
>2 \text { mg/dl), Mallampati } \\
3 \text { or } 4 \text {, epilepsy, allergy, } \\
\text { receiving long term } \\
\text { steroid therapy, } \\
\text { mechanically ventilated } \\
\text { preoperatively }\end{array}$ & $\begin{array}{l}\text { All patients: identical } \\
\text { doses of morphine and } \\
\text { promethazine } \\
\text { Induction performed } \\
\text { using infusion of IV } \\
\text { anesthetic titrated to } \\
\text { BIS <50 } \\
\text { Group P: } 0.5 \\
\text { mg/kg/min propofol } \\
\text { Group II: } 0.05 \\
\text { mg/kg/min etomidate } \\
\text { Hemodynamic } \\
\text { measurements recorded } \\
\text { before induction, after } \\
\text { induction, after } \\
\text { intubation, and seven } \\
\text { minutes post induction }\end{array}$ & $\begin{array}{l}\text { HR increased to a } \\
\text { larger degree in group } \\
\text { E } \\
\text { CI decreased in both } \\
\text { groups in a non- } \\
\text { statistically significant } \\
\text { manner } \\
\text { MAP decreased in } \\
\text { Group P more than } \\
\text { Group E, however the } \\
\text { difference was not } \\
\text { statistically significant } \\
\text { SVR decreased in } \\
\text { group P in a moderately } \\
\text { significant manner } \\
\text { (p=0.022) } \\
\text { After intubation, SVR } \\
\text { increased in both } \\
\text { groups, with group E } \\
\text { demonstrating a } \\
\text { statistically significant } \\
\text { larger increase than } \\
\text { group P (p=0.003) }\end{array}$ & Not discussed \\
\hline
\end{tabular}


Note: IV-intravenous, CABG - coronary artery bypass grafting, CPB-cardiopulmonary bypass, ASA-American Association of Anesthesiologists, LV-left ventricle, CHF-congestive heart failure, MAP-mean arterial pressure, CI-cardiac index, SVR-systemic vascular resistance 
Table B-5

Kamath, M. R., Kamath, S., \& Patla, K. P. (2016). Propofol or etomidate: Does it genuinely matter for induction in cardiac surgical procedures? Indian Journal of Clinical Anesthesia, 3(4), 551-555. https://doi.org/10.18231/2394-4994.2016.0012

\begin{tabular}{|c|c|c|c|c|c|}
\hline Purpose & Project Design & Site, Sample & Method & Results & Limitations \\
\hline $\begin{array}{l}\text { To compare propofol } \\
\text { with etomidate with } \\
\text { respect to } \\
\text { hemodynamic stability } \\
\text { during induction of } \\
\text { anesthesia for open } \\
\text { cardiac surgical } \\
\text { procedures }\end{array}$ & $\begin{array}{l}\text { Prospective, } \\
\text { randomized study of } 60 \\
\text { patients randomly } \\
\text { divided into two } \\
\text { groups, each comprised } \\
\text { of } 30 \text { patients, } \\
\text { undergoing elective } \\
\text { cardiac surgical } \\
\text { procedures } \\
\text { Group A ( } \mathrm{n}=30 \text { ): } \\
\text { Received propofol as } \\
\text { IV induction agent } \\
\text { Group B (n=30): } \\
\text { Received etomidate as } \\
\text { IV induction agent } \\
\text { Randomization } \\
\text { performed using closed } \\
\text { envelope technique }\end{array}$ & $\begin{array}{l}\text { Site: Not provided. } \\
\text { Authors are affiliated } \\
\text { with KS Hegde Medical } \\
\text { Academy, Mangalore, } \\
\text { India } \\
\text { Sixty adult patients, } \\
\text { ages 20-60 } \\
\text { Excluded: Not provided }\end{array}$ & $\begin{array}{l}\text { All patients: } \\
\text { premedicated orally } \\
\text { with } 50 \mathrm{mg} \text { ranitidine } \\
\text { and } 10 \mathrm{mg} \text { diazepam } \\
\text { night before surgery } \\
\text { Received fentanyl } 5 \\
\mathrm{mcg} / \mathrm{kg} \text { and midazolam } \\
0.05 \mathrm{mg} / \mathrm{kg} \text { pre- } \\
\text { induction } \\
\text { Group A: } 1.5 \mathrm{mg} / \mathrm{kg} \\
\text { propofol } \\
\text { Group B: } 0.2 \mathrm{mg} / \mathrm{kg} \\
\text { etomidate } \\
\text { Hemodynamic } \\
\text { measurements recorded } \\
\text { before induction, after } \\
\text { induction, after } \\
\text { intubation, and five } \\
\text { minutes post induction }\end{array}$ & $\begin{array}{l}\text { Propofol group: } \\
\text { After induction: } \\
\text { Statistically significant } \\
\text { decrease in SBP, MAP, } \\
\text { CO and CI ( }<<0.05) \\
\text { After intubation: } \\
\text { Statistically significant } \\
\text { increase in DBP, CO } \\
\text { and CI (p<0.05) } \\
\text { Five minutes after } \\
\text { intubation: } \\
\text { Statistically significant } \\
\text { increase in MAP, CVP, } \\
\text { and PCWP in propofol } \\
\text { (p<0.05) } \\
\text { No significant changes } \\
\text { in any other parameters } \\
\text { at these times } \\
\text { Etomidate group: } \\
\text { No significant changes } \\
\text { at any time }\end{array}$ & Not discussed \\
\hline
\end{tabular}


Note: IV-intravenous, SBP-systolic blood pressure, DBP-diastolic blood pressure, MAP-mean arterial pressure, CO-cardiac output, CI-cardiac index, SVRsystemic vascular resistance, PCWP-pulmonary capillary wedge pressure 
Table B-6

Soleimani, A., Heidari, N., Habibi, M. R., Kiabi, F. H., Khademloo, M., Zeydi, A. E., \& Sohrabi, F. B. (2017). Comparing hemodynamic responses to diazepam, propofol and etomidate during anesthesia induction in patients with left ventricular dysfunction undergoing coronary artery bypass graft surgery: A double-blind, randomized clinical trial. Medical Archives, 71(3), $198-203$.

https://doi.org/10.5455/medarh.2017.71.198-203

\begin{tabular}{|c|c|c|c|c|c|}
\hline Purpose & Project Design & Site, Sample & Method & Results & Limitations \\
\hline $\begin{array}{l}\text { To compare the } \\
\text { hemodynamic } \\
\text { responses to propofol, } \\
\text { etomidate and diazepam } \\
\text { following anesthesia } \\
\text { induction, laryngoscopy } \\
\text { and intubation in } \\
\text { CABG surgery patients } \\
\text { with low ejection } \\
\text { fraction (EF) }\end{array}$ & $\begin{array}{l}\text { Double-blind } \\
\text { randomized clinical } \\
\text { study of } 150 \text { patients } \\
\text { scheduled for elective } \\
\text { CABG with CPB, } \\
\text { randomly allocated into } \\
\text { three groups of } 50 \\
\text { Group A: Received } \\
\text { propofol as IV } \\
\text { induction agent } \\
\text { Group B: Received } \\
\text { etomidate as IV } \\
\text { induction agent } \\
\text { Group C: Received } \\
\text { diazepam as IV } \\
\text { induction agent } \\
\text { Randomization } \\
\text { performed using closed } \\
\text { envelope technique }\end{array}$ & $\begin{array}{l}\text { Site: Cardiac surgery } \\
\text { unit and open heart } \\
\text { intensive care unit of a } \\
\text { teaching hospital } \\
\text { affiliated with } \\
\text { Mazandaran University } \\
\text { of Medical Sciences, } \\
\text { Sari, Iran } \\
150 \text { adult patients with } \\
\text { CAD and left } \\
\text { ventricular dysfunction } \\
\text { (EF } \leq 35 \% \text { ), and stable } \\
\text { hemodynamics } \\
\text { Excluded: Patients with } \\
\text { history of chronic } \\
\text { inflammatory disease, } \\
\text { endocarditis, adrenal } \\
\text { insufficiency, sepsis, } \\
\text { steroid use within } 6 \\
\text { months, difficult } \\
\text { intubation, combined } \\
\text { CABG/other surgery }\end{array}$ & $\begin{array}{l}\text { All patients: } \\
\text { Premedicated with } 2 \\
\mathrm{mcg} / \mathrm{kg} \text { fentanyl and } \\
0.03 \mathrm{mcg} / \mathrm{kg} \text { midazolam } \\
1.5 \mathrm{mg} / \mathrm{kg} \\
\text { succinylcholine after } \\
\text { induction to facilitate } \\
\text { intubation } \\
\text { Group A ( } \mathrm{n}=50 \text { ): } \\
1.5 \mathrm{mg} / \mathrm{kg} \text { propofol } \\
\text { Group B ( } \mathrm{n}=50) \text { : } \\
0.2 \mathrm{mg} / \mathrm{kg} \text { etomidate } \\
\text { Group C ( } \mathrm{n}=50 \text { ): } \\
0.3 \mathrm{mg} / \mathrm{kg} \text { diazepam } \\
\text { Hemodynamic } \\
\text { measurements recorded } \\
\text { before induction, before } \\
\text { larygoscopy, one and } \\
\text { five minutes post } \\
\text { induction }\end{array}$ & $\begin{array}{l}\text { Statistically significant } \\
\text { decrease in SBP, DBP } \\
\text { and MAP in all three } \\
\text { groups one minute after } \\
\text { induction ( }<<0.001 \text { ). } \\
\text { Decrease remained for } \\
\text { other measurements in } \\
\text { propofol group } \\
\text { ( }<<0.001 \text { ), with } \\
\text { recovery to near } \\
\text { baseline in other groups } \\
\\
\text { A statistically } \\
\text { significant percentage } \\
\text { of patients in the } \\
\text { propofol group required } \\
\text { rescue administration of } \\
\text { ephedrine compared } \\
\text { with the other groups } \\
\text { ( }<<0.001 \text { ). }\end{array}$ & $\begin{array}{l}\text { Dosages per kilogram } \\
\text { of body weight may be } \\
\text { unequally distributed } \\
\text { between groups, and be } \\
\text { a confounding variable }\end{array}$ \\
\hline
\end{tabular}


Note: IV-intravenous, CAD-coronary artery disease, EF=ejection fraction, SBP-systolic blood pressure, DBP-diastolic blood pressure, MAP-mean arterial pressure, HR-heart rate 
Table B-7

Mala, R., \& Narmada, S. (2017). Prospective randomised study comparing the haemodynamic and endocrine response to induction with etomidate and propofol in patients undergoing cardiac surgery on cardiopulmonary bypass. Indian Journal of Applied Research, 7(10), 145-146. Retrieved from https://www.worldwidejournals.com/indian-journal-of-applied-research (IJAR)/fileview/October_2017_1506777489_54.pdf

\begin{tabular}{|c|c|c|c|c|c|}
\hline Purpose & Project Design & Site, Sample & Method & Results & Limitations \\
\hline $\begin{array}{l}\text { To compare the } \\
\text { hemodynamic profile } \\
\text { and the hormonal } \\
\text { alteration between } \\
\text { etomidate and propofol } \\
\text { following induction in } \\
\text { cardiac surgery, } \\
\text { particularly in patients } \\
\text { undergoing coronary } \\
\text { artery bypass surgery } \\
\text { on cardiopulmonary } \\
\text { bypass }\end{array}$ & $\begin{array}{l}\text { Prospective randomized } \\
\text { study of } 30 \text { patients } \\
\text { scheduled for elective } \\
\text { CABG with CPB, } \\
\text { randomly allocated into } \\
\text { two groups of } 15 \\
\text { Propofol Group ( } \mathrm{n}=15) \text { : } \\
\text { Received } 2 \mathrm{mg} / \mathrm{kg} \\
\text { propofol as IV } \\
\text { induction agent } \\
\text { Etomidate Group } \\
\text { (n=15): Received } 0.2 \\
\text { mg/kg etomidate as IV } \\
\text { induction agent } \\
\text { Randomization } \\
\text { performed using closed } \\
\text { envelope technique }\end{array}$ & $\begin{array}{l}\text { Site: Not Provided } \\
\text { Sample: } \\
30 \text { adult patients (ages } \\
\text { 18-60), ASA II and III, } \\
\text { Mallampati I and II, } \\
\text { with normal LV } \\
\text { function } \\
\text { Excluded: History of } \\
\text { LV dysfunction, } \\
\text { arrhythmia, CHF, pre- } \\
\text { op mechanical } \\
\text { ventilation, current } \\
\text { steroid therapy, existing } \\
\text { bleeding } \\
\text { disorder/coagulopathy, } \\
\text { renal dysfunction } \\
\text { (creatinine }>2.0 \\
\text { mg.dL), difficult } \\
\text { airway, poor lung } \\
\text { compliance, any other } \\
\text { comorbidities except } \\
\text { diabetes or } \\
\text { hypertension }\end{array}$ & $\begin{array}{l}\text { Hemodynamic } \\
\text { measurements recorded } \\
\text { before induction, at } \\
\text { one, two and three } \\
\text { minutes after induction, } \\
\text { and at } 1 \text { and five } \\
\text { minutes after intubation }\end{array}$ & $\begin{array}{l}\text { Statistically significant } \\
\text { decrease in SBP from } \\
\text { baseline after induction, } \\
\text { much lower } 5 \text { minutes } \\
\text { after intubation in the } \\
\text { propofol group } \\
\text { ( }<<0.05 \text { ) } \\
\text { Statistically significant } \\
\text { decrease in CI from } \\
\text { baseline, two, and three } \\
\text { minutes following } \\
\text { induction in the } \\
\text { propofol group } \\
\text { (p<0.05) } \\
\text { Serum cortisol } 50 \% \text { of } \\
\text { baseline at initiation of } \\
\text { CPB in etomidate } \\
\text { group, almost double } \\
\text { baseline in propofol } \\
\text { group (p }<0.05 \text { ) }\end{array}$ & $\begin{array}{l}\text { Dosages per kilogram } \\
\text { of body weight may be } \\
\text { unequally distributed } \\
\text { between groups, and be } \\
\text { a confounding variable }\end{array}$ \\
\hline
\end{tabular}


Note: IV-intravenous, CAD-coronary artery disease, EF=ejection fraction, SBP-systolic blood pressure, DBP-diastolic blood pressure, MAP-mean arterial pressure, HR-heart rate 
Table B-8

Meena, R., Sharma, R. S., Ranawat, P., Saiyed, A., \& Verma, I. (2017). Comparison of hemodynamic and serum cortisol levels in response to anesthetic induction with etomidate or propofol in patients undergoing CABG surgery. Indian Journal of Clinical Anaesthesia, 4(3), 345-351. https://doi.org/10.18231/2394-4994.2017.0071

\begin{tabular}{|c|c|c|c|c|c|}
\hline Purpose & Project Design & Site, Sample & Method & Results & Limitations \\
\hline $\begin{array}{l}\text { To compare the effects } \\
\text { of induction agents } \\
\text { etomidate and propofol } \\
\text { on hemodynamic and } \\
\text { serum cortisol levels in } \\
\text { patients undergoing } \\
\text { coronary artery bypass } \\
\text { graft surgery on } \\
\text { cardiopulmonary } \\
\text { bypass }\end{array}$ & $\begin{array}{l}\text { Prospective randomized } \\
\text { study of } 60 \text { patients } \\
\text { scheduled for elective } \\
\text { CABG with CPB, } \\
\text { randomly allocated into } \\
\text { two groups of } 15 \\
\text { Group A (n=30): } \\
\text { Received etomidate } 0.3 \\
\text { mg/kg as IV induction } \\
\text { agent } \\
\text { Group B (n=30): } \\
\text { Received propofol } 2.0 \\
\text { mg/kg as IV induction } \\
\text { agent } \\
\text { Randomization } \\
\text { performed by “chit in } \\
\text { the box" method }\end{array}$ & $\begin{array}{l}\text { Site: Department of } \\
\text { Anesthesiology, S.M.S. } \\
\text { hospital and attached } \\
\text { group of hospitals, } \\
\text { Jaipur, Rajasthan, India } \\
\text { Sample: } \\
60 \text { adult patients (ages } \\
25-60) \text {, ASA II and III, } \\
\text { with triple vessel } \\
\text { disease and LVEF } \\
<45 \% \text {, presenting for } \\
\text { elective CABG } \\
\text { Excluded: Patients with } \\
\text { decompensated heart } \\
\text { failure, renal } \\
\text { dysfunction, bleeding } \\
\text { and coagulation } \\
\text { abnormalities, pre- } \\
\text { existing arrhythmias, on } \\
\text { mechanical ventilation, } \\
\text { on steroid therapy, } \\
\text { undergoing emergency } \\
\text { procedure }\end{array}$ & $\begin{array}{l}\text { All patients: } \\
\text { NPO x eight hours } \\
\text { Morphine } 0.1 \mathrm{mg} / \mathrm{kg} \text { IM } \\
\text { and promethazine } 0.5 \\
\text { mg / kg IM } 30 \text { minutes } \\
\text { prior to induction } \\
\text { Fentanyl } 4 \text { mcg/kg, then } \\
\text { baseline parameters } \\
\text { (HR, SBP, DBP, MAP, } \\
\text { CVP, PCWP, CO, CI, } \\
\text { SVR, SVRI, PVR, } \\
\text { PVRI) were recorded } \\
\text { over ten minutes with } \\
\text { pre-oxygenation, after } \\
\text { which induction was } \\
\text { performed. } \\
\text { Hemodynamic } \\
\text { measurements and } \\
\text { cortisol level recorded } 2 \\
\text { minutes after induction } \\
\text { and after intubation. }\end{array}$ & $\begin{array}{l}\text { Cortisol level: } \\
\text { Group A: significant } \\
\text { decrease (up to } 60 \% \text { ) } \\
\text { from baseline coming } \\
\text { off bypass ( } \mathrm{p}=0.0036 \text { ), } \\
\text { significant increase } \\
\text { from baseline } 24 \text { hours } \\
\text { post op } \\
\quad \text { Group B: Large, but } \\
\text { statistically } \\
\text { insignificant increase } \\
\text { (up to double) coming } \\
\text { off bypass, also } \\
\text { significant increase } 24 \\
\text { hours post op } \\
\text { Hemodynamics: } \\
\text { Significant decrease in } \\
\text { SBP ( } p=0.0007), \text { DBP } \\
\text { (p=0.0371), SVR } \\
\text { (p=0.0369), SVRI } \\
\text { (p=0.0120) after } \\
\text { induction in group B } \\
\text { Large, but statistically } \\
\text { insignificant increase in }\end{array}$ & Small sample size \\
\hline
\end{tabular}




\begin{tabular}{|l|l|l|l|l|l|}
\hline & & & $\begin{array}{l}\text { HR and SBP after } \\
\text { intubation in group A }\end{array}$ & & \\
\hline
\end{tabular}

Note: CABG-coronary artery bypass graft, CPB-cardiopulmonary bypass, IV-intravenous, , ASA-American Society of Anesthesiologists, LVEF-left ventricular ejection fraction, NPO-nothing per os, IM-intramuscular, HR-heart rate, SBP-systolic blood pressure, DBP-diastolic blood pressure, MAP-mean arterial pressure, CVP-central venous pressure, PCWP-pulmonary capillary wedge pressure, CO-cardiac output, CI-cardiac index, SVR-systemic vascular resistance, SVRIsystemic vascular resistance index, PVR-pulmonary vascular resistance, PVRI-pulmonary vascular resistance index 
Table B-9

Hannam, J. A., Mitchell, S. J., Cumin, D., Frampton, C., Merry, A. F., Moore, M. R., \& Kruger, C. J. (2019). Haemodynamic profiles of etomidate vs propofol for induction of anaesthesia: A randomised controlled trial in patients undergoing cardiac surgery. British Journal of Anaesthesia, 122(2), 198-205. https://doi.org/10.1016/j.bja.2018.09.027

\begin{tabular}{|c|c|c|c|c|c|}
\hline Purpose & Project Design & Site, Sample & Method & Results & Limitations \\
\hline $\begin{array}{l}\text { To test the hypothesis } \\
\text { that etomidate is } \\
\text { superior to propofol for } \\
\text { induction of anesthesia } \\
\text { in relation to } \\
\text { hemodynamic stability } \\
\text { over the first } 10 \\
\text { minutes after induction, } \\
\text { in patients undergoing } \\
\text { cardiac surgery }\end{array}$ & $\begin{array}{l}\text { Randomized, controlled } \\
\text { superiority trial with } \\
\text { open-label (unblended) } \\
\text { and blinded phases. } \\
\text { Phase I (n=76): open } \\
\text { label - anesthetist not } \\
\text { blinded } \\
\text { - Propofol } \\
\text { Group ( }=40) \text { : } \\
\text { Etomidate } \\
\quad \text { Group ( } \mathrm{n}=36) \\
\text { Phase II (n=74): closed- } \\
\text { label - all clinical staff } \\
\text { blinded } \\
\text { - } \\
\text { Propofol } \\
\text { Group ( } \mathrm{n}=35) \text { : } \\
\text { Etomidate } \\
\text { Group ( } \mathrm{n}=39 \text { ) }\end{array}$ & $\begin{array}{l}\text { Site: Green Lane } \\
\text { Cardiothoracic Surgery } \\
\text { Unit, Auckland, New } \\
\text { Zealand } \\
\text { Sample: } \\
150 \text { adult patients (ages } \\
18 \text {-60), ASA II-IV, } \\
\text { undergoing elective } \\
\text { CABG, valve surgery, } \\
\text { combination } \\
\text { CABG/valve surgery, } \\
\text { and thoracic aorta } \\
\text { surgery } \\
\text { Excluded: Documented } \\
\text { allergy to propofol or } \\
\text { etomidate, scheduled } \\
\text { for transplant }\end{array}$ & $\begin{array}{l}\text { Patients were pre- } \\
\text { medicated with } \\
\text { midazolam and fentanyl } \\
\text { at the anesthetists' } \\
\text { discretion, with non- } \\
\text { standardized doses } \\
\text { chosen by the } \\
\text { anesthetist. Induction } \\
\text { was accomplished with } \\
\text { titration of the allocated } \\
\text { medication to loss of } \\
\text { responsiveness to } \\
\text { verbal stimuli. The } \\
\text { remainder of the } \\
\text { anesthetic appeared to } \\
\text { be standardized. } \\
\text { MAP recorded every } 30 \\
\text { seconds. Primary } \\
\text { endpoint was area } \\
\text { under the baseline MAP } \\
\text { over the first } 10 \\
\text { minutes after induction }\end{array}$ & $\begin{array}{l}34 \% \text { greater reduction } \\
\text { in MAP with propofol } \\
\text { than with etomidate } \\
(p=0.009) .\end{array}$ & $\begin{array}{l}\text { Unequal numbers of } \\
\text { study subjects between } \\
\text { phases and between } \\
\text { anesthetics within each } \\
\text { phase } \\
\text { Lack of standardized } \\
\text { protocol aside from the } \\
\text { study intervention } \\
\text { could introduce } \\
\text { confounding factors } \\
\text { related to anesthesia } \\
\text { provider decision- } \\
\text { making and practice } \\
\text { that affect results }\end{array}$ \\
\hline
\end{tabular}


Note: ASA-American Society of Anesthesiologists, CABG-coronary artery bypass graft, MAP-mean arterial pressure 


\section{Appendix C}

Table C-1

Basagan-Mogol, E., Goren, S., Korfali, G., Turker, G., \& Kaya, F. N. (2010). Induction of anesthesia in coronary artery bypass graft surgery: The hemodynamic and analgesic effects of ketamine. Clinics, 65(2), 133-138. https://doi.org/10.1590/S1807 59322010000200003

\begin{tabular}{|c|c|c|c|c|c|c|c|c|}
\hline & Propofol & Etomidate \\
\hline Heart Rate & NR & 0 \\
\hline Systolic Blood Pressure & NR \\
\hline Diastolic Blood Pressure & $\downarrow$ & NR \\
\hline Mean Arterial Pressure & 0 & 0 \\
\hline Cardiac Output & 0 \\
\hline Cardiac Index & $\downarrow$ \\
\hline SVR & NR \\
\hline Endocrine Response & 0 \\
\hline
\end{tabular}

Note: NR-not reported, arrows represent statistically significant findings, zeroes represent lack of statistically significant findings, blacked out columns signify that the particular medication was not included in the study 
Table C-2

Pandey, A. K., Makhija, N., Chauhan, S., Das, S., Kiran, U., Bisoi, A. K., \& Lakshmy, R. (2012). The effects of etomidate and propofol induction on hemodynamic and endocrine response in patients undergoing coronary artery bypass graft surgery on cardiopulmonary bypass. World Journal of Cardiovascular Surgery, 2(3), 48-53. https://doi.org/10.4236/wjcs.2012.2301

\begin{tabular}{|c|c|c|}
\hline & Propofol & Etomidate \\
\hline Heart Rate & 0 & 0 \\
\hline Systolic Blood Pressure & $\downarrow$ & 0 \\
\hline Diastolic Blood Pressure & $\downarrow$ & 0 \\
\hline Mean Arterial Pressure & NR & NR \\
\hline Cardiac Output & 0 & 0 \\
\hline Cardiac Index & 0 & 0 \\
\hline SVR & $\downarrow$ & 0 \\
\hline Endocrine Response & $\uparrow$ & $\downarrow$ \\
\hline
\end{tabular}

Note: NR-not reported, arrows represent statistically significant findings, zeroes represent lack of statistically significant findings, blacked out columns signify that the particular medication was not included in the study 
Table C-3

Kaushal, R. P., Vatal, A., \& Pathak, R. (2015). Effect of etomidate and propofol induction on hemodynamic and endocrine response in patients undergoing coronary artery bypass grafting/mitral valve and aortic valve replacement surgery on cardiopulmonary bypass. Annals of Cardiac Anesthesia, 18(2), 172-178. https://doi.org/10.4103/0971-9784.154470

\begin{tabular}{|c|c|c|}
\hline & Propofol & Etomidate \\
\hline Heart Rate & 0 & 0 \\
\hline Systolic Blood Pressure & $\downarrow$ & 0 \\
\hline Diastolic Blood Pressure & $\downarrow$ & 0 \\
\hline Mean Arterial Pressure & $\downarrow$ & 0 \\
\hline Cardiac Output & $\downarrow$ & 0 \\
\hline Cardiac Index & $\downarrow$ & 0 \\
\hline SVR & $\uparrow$ & 0 \\
\hline Endocrine Response & $\downarrow$ & $\downarrow$ \\
\hline
\end{tabular}

Note: Arrows represent statistically significant findings, zeroes represent lack of statistically significant findings, blacked out columns signify that the particular medication was not included in the study 
Table C-4

Shivanna, S., Priye, S., Jagannath, S., Kadli, C., Mayuri, M., Vikas, V., ... Reddy, D. (2015). A comparative study of haemodynamic effects of propofol and etomidate as an induction agent in coronary artery surgery. Journal of Evolution of Medical and Dental Sciences, 4(1), 2278-4748. https://doi.org/10.14260/jemds/2015/88

\begin{tabular}{|c|c|c|c|}
\hline & Propofol & Etomidate \\
\hline Heart Rate & 0 & 0 \\
\hline Systolic Blood Pressure & NR & NR \\
\hline Diastolic Blood Pressure & NR & NR \\
\hline Mean Arterial Pressure & $\downarrow$ & $\downarrow$ \\
\hline Cardiac Output & NR & NR \\
\hline Cardiac Index & 0 & 0 \\
\hline SVR & $\downarrow$ & $\uparrow$ (post intubation) \\
\hline Endocrine Response & NR & NR \\
\hline
\end{tabular}

Note: NR-not reported, arrows represent statistically significant findings, zeroes represent lack of statistically significant findings, blacked out columns signify that the particular medication was not included in the study 
Table C-5

Kamath, M. R., Kamath, S., \& Patla, K. P. (2016). Propofol or etomidate: Does it genuinely matter for induction in cardiac surgical procedures? Indian Journal of Clinical Anesthesia, 3(4), 551-555. https://doi.org/10.18231/2394-4994.2016.0012

\begin{tabular}{|c|c|c|}
\hline & Propofol & Etomidate \\
\hline Heart Rate & 0 & 0 \\
\hline Systolic Blood Pressure & $\downarrow$ & 0 \\
\hline Diastolic Blood Pressure & 0 & 0 \\
\hline Mean Arterial Pressure & $\downarrow$ & 0 \\
\hline Cardiac Output & $\downarrow$ & 0 \\
\hline Cardiac Index & $\downarrow$ & 0 \\
\hline SVR & 0 & 0 \\
\hline Endocrine Response & NR & NR \\
\hline
\end{tabular}

Note: NR-not reported, arrows represent statistically significant findings, zeroes represent lack of statistically significant findings, blacked out columns signify that the particular medication was not included in the study 
Table C-6

Soleimani, A., Heidari, N., Habibi, M. R., Kiabi, F. H., Khademloo, M., Zeydi, A. E., \& Sohrabi, F. B. (2017). Comparing hemodynamic responses to diazepam, propofol and etomidate during anesthesia induction in patients with left ventricular dysfunction undergoing coronary artery bypass graft surgery: A double-blind, randomized clinical trial. Medical Archives, 71(3), $198-203$.

https://doi.org/10.5455/medarh.2017.71.198-203

\begin{tabular}{|c|c|c|c|}
\hline & Propofol & Etomidate & $\downarrow$ \\
\hline Heart Rate & $\downarrow$ & 0 \\
\hline Diastolic Blood Pressure & $\downarrow$ & 0 \\
\hline Mean Arterial Pressure & $\downarrow$ & 0 \\
\hline Cardiac Output & $\downarrow$ & NR \\
\hline Cardiac Index & NR & NR \\
\hline SVR & NR & NR \\
\hline Endocrine Response & NR & NR \\
\hline
\end{tabular}

Note: NR-not reported, arrows represent statistically significant findings, zeroes represent lack of statistically significant findings, blacked out columns signify that the particular medication was not included in the study 
Table C-7

Mala, R., \& Narmada, S. (2017). Prospective randomised study comparing the haemodynamic and endocrine response to induction with etomidate and propofol in patients undergoing cardiac surgery on cardiopulmonary bypass. Indian Journal of Applied Research, 7(10), 145-146. Retrieved from https://www.worldwidejournals.com/indian-journal-of-applied-research (IJAR)/fileview/October_2017_1506777489_54.pdf

\begin{tabular}{|c|c|c|}
\hline & Propofol & Etomidate \\
\hline Heart Rate & $\downarrow$ & $\downarrow$ \\
\hline Systolic Blood Pressure & $\downarrow$ & 0 \\
\hline Diastolic Blood Pressure & 0 & 0 \\
\hline Mean Arterial Pressure & $\downarrow$ & 0 \\
\hline Cardiac Output & NR & NR \\
\hline Cardiac Index & $\downarrow$ & 0 \\
\hline SVR & NR & NR \\
\hline Endocrine Response & $\uparrow$ & $\downarrow$ \\
\hline
\end{tabular}

Note: NR-not reported, arrows represent statistically significant findings, zeroes represent lack of statistically significant findings, blacked out columns signify that the particular medication was not included in the study 
Table C-8

Meena, R., Sharma, R. S., Ranawat, P., Saiyed, A., \& Verma, I. (2017). Comparison of hemodynamic and serum cortisol levels in response to anesthetic induction with etomidate or propofol in patients undergoing CABG surgery. Indian Journal of Clinical Anaesthesia, 4(3), 345-351. https://doi.org/10.18231/2394-4994.2017.0071

\begin{tabular}{|c|c|c|c|}
\hline & Propofol & Etomidate & $\downarrow$ \\
\hline Heart Rate & $\downarrow$ & 0 \\
\hline Systolic Blood Pressure & $\downarrow$ & 0 \\
\hline Diastolic Blood Pressure & $\downarrow$ & 0 \\
\hline Mean Arterial Pressure & $\downarrow$ & 0 \\
\hline Cardiac Output & 0 & 0 \\
\hline Cardiac Index & $\downarrow$ & 0 \\
\hline SVR & $\uparrow$ & $\downarrow$ \\
\hline
\end{tabular}

Note: NR-not reported, arrows represent statistically significant findings, zeroes represent lack of statistically significant findings, blacked out columns signify that the particular medication was not included in the study 
Table C-9

Hannam, J. A., Mitchell, S. J., Cumin, D., Frampton, C., Merry, A. F., Moore, M. R., \& Kruger, C. J. (2019). Haemodynamic profiles of etomidate vs propofol for induction of anaesthesia: A randomised controlled trial in patients undergoing cardiac surgery. British Journal of Anaesthesia, 122(2), 198-205. https://doi.org/10.1016/j.bja.2018.09.027

\begin{tabular}{|c|c|c|}
\hline & Propofol & Etomidate \\
\hline Heart Rate & NR & NR \\
\hline Systolic Blood Pressure & NR & NR \\
\hline Diastolic Blood Pressure & NR & NR \\
\hline Mean Arterial Pressure & $\downarrow$ & 0 \\
\hline Cardiac Output & NR & NR \\
\hline Cardiac Index & NR & NR \\
\hline SVR & NR & NR \\
\hline Endocrine Response & NR & NR \\
\hline
\end{tabular}

Note: NR-not reported, arrows represent statistically significant findings, zeroes represent lack of statistically significant findings, blacked out columns signify that the particular medication was not included in the study 


\section{Appendix D}

\section{Table D-1}

Critical Appraisal Skills Programme (CASP) Randomized Controlled Trials Checklist

Basagan-Mogol, E., Goren, S., Korfali, G., Turker, G., \& Kaya, F. N. (2010). Induction of anesthesia in coronary artery bypass graft surgery: The hemodynamic and analgesic effects of ketamine. Clinics, 65(2), 133-138. https://doi.org/10.1590/S180759322010000200003

D) Are the results of the trial valid?

12. Did the trial address a clearly focused issue?

13. Was the assignment of patients to treatments randomized?

14. Were all of the patients who entered the trial properly accounted for at its conclusion?

15. Were patients, health workers, and study personnel "blind" to treatment?

16. Were the groups similar at the start of the trial?

17. Aside from the experimental intervention, were groups treated equally?

E) What are the results?

18. How large was the treatment effect?

19. How precise was the estimate of the treatment effect?

F) Will the results help locally?

20. Can the results be applied in your context? (or to the local population?)

21 . Were all clinically important outcomes considered?

22. Are the benefits worth the harms?
YES

CAN'T TELL

NO

$\mathbf{X}$

$\mathbf{X}$

$\mathbf{X}$

$\mathbf{X}$

$\mathbf{X}$

$\mathbf{X}$

Not discussed

Not discussed

YES

CAN'T TELL

NO

X

X

X 


\section{Table D-2}

Critical Appraisal Skills Programme (CASP) Randomized Controlled Trials Checklist

Pandey, A. K., Makhija, N., Chauhan, S., Das, S., Kiran, U., Bisoi, A. K., \& Lakshmy, R. (2012). The effects of etomidate and propofol induction on hemodynamic and endocrine response in patients undergoing coronary artery bypass graft surgery on cardiopulmonary bypass. World Journal of Cardiovascular Surgery, 2(3), 48-53.

https://doi.org/10.4236/wjcs.2012.23011

\section{A) Are the results of the trial valid?}

1. Did the trial address a clearly focused issue?

2. Was the assignment of patients to treatments randomized?

3. Were all of the patients who entered the trial properly accounted for at its conclusion?

4. Were patients, health workers, and study personnel "blind" to treatment?

5. Were the groups similar at the start of the trial?

6. Aside from the experimental intervention, were groups treated equally?

B) What are the results?

7. How large was the treatment effect?

8. How precise was the estimate of the treatment effect?

C) Will the results help locally?

9. Can the results be applied in your context? (or to the local population?)

10. Were all clinically important outcomes considered?

11. Are the benefits worth the harms?
YES

\section{CAN'T TELL}

NO

X

X

$\mathbf{X}$

$\mathbf{X}$

X

X

Not discussed

Not discussed

YES

CAN'T TELL

NO

X

X

X 


\section{Table D-3}

Critical Appraisal Skills Programme (CASP) Randomized Controlled Trials Checklist

Kaushal, R. P., Vatal, A., \& Pathak, R. (2015). Effect of etomidate and propofol induction on hemodynamic and endocrine response in patients undergoing coronary artery bypass grafting/mitral valve and aortic valve replacement surgery on cardiopulmonary bypass. Annals of Cardiac Anesthesia, 18(2), 172-178. https://doi.org/10.4103/0971-9784.154470

A) Are the results of the trial valid?

1. Did the trial address a clearly focused issue?

2. Was the assignment of patients to treatments randomized?

3. Were all of the patients who entered the trial properly accounted for at its conclusion?

4. Were patients, health workers, and study personnel "blind" to treatment?

5. Were the groups similar at the start of the trial?

6. Aside from the experimental intervention, were groups treated equally?

B) What are the results?

7. How large was the treatment effect?

8. How precise was the estimate of the treatment effect?

C) Will the results help locally?

9. Can the results be applied in your context? (or to the local population?)

10. Were all clinically important outcomes considered?

11. Are the benefits worth the harms?
YES

$\mathbf{X}$

$\mathbf{X}$

$\mathbf{X}$

CAN'T TELL

NO

\section{$\mathbf{X}$}

$\mathbf{X}$

$\mathbf{X}$

Not discussed

Not discussed

YES CAN'T TELL

NO

X

X

X 


\section{Table D-4}

Critical Appraisal Skills Programme (CASP) Randomized Controlled Trials Checklist

Shivanna, S., Priye, S., Jagannath, S., Kadli, C., Mayuri, M., Vikas, V., ... Reddy, D. (2015). A comparative study of haemodynamic effects of propofol and etomidate as an induction agent in coronary artery surgery. Journal of Evolution of Medical and Dental Sciences, 4(1), 2278-4748. https://doi.org/10.14260/jemds/2015/88

A) Are the results of the trial valid?

1. Did the trial address a clearly focused issue?

2. Was the assignment of patients to treatments randomized?

3. Were all of the patients who entered the trial properly accounted for at its conclusion?

4. Were patients, health workers, and study personnel "blind" to treatment?

5. Were the groups similar at the start of the trial?

6. Aside from the experimental intervention, were groups treated equally?

B) What are the results?

7. How large was the treatment effect?

8. How precise was the estimate of the treatment effect?

C) Will the results help locally?

9. Can the results be applied in your context? (or to the local population?)

10. Were all clinically important outcomes considered?

11. Are the benefits worth the harms?
YES

$\mathbf{X}$

$\mathbf{X}$

$\mathbf{X}$

$\mathbf{X}$

$\mathbf{X}$

$\mathbf{X}$

CAN'T TELL

NO

Not discussed

Not discussed

YES

CAN'T TELL

NO

$\mathbf{X}$

$\mathbf{X}$

X 


\section{Table D-5}

Critical Appraisal Skills Programme (CASP) Randomized Controlled Trials Checklist

Kamath, M. R., Kamath, S., \& Patla, K. P. (2016). Propofol or etomidate: Does it genuinely matter for induction in cardiac surgical procedures? Indian Journal of Clinical Anesthesia, 3(4), 551-555. https://doi.org/10.18231/2394-4994.2016.0012

A) Are the results of the trial valid?

1. Did the trial address a clearly focused issue?

2. Was the assignment of patients to treatments randomized?

3. Were all of the patients who entered the trial properly accounted for at its conclusion?

4. Were patients, health workers, and study personnel "blind" to treatment?

5. Were the groups similar at the start of the trial?

6. Aside from the experimental intervention, were groups treated equally?

B) What are the results?

7. How large was the treatment effect?

8. How precise was the estimate of the treatment effect?

C) Will the results help locally?

9. Can the results be applied in your context? (or to the local population?)

10. Were all clinically important outcomes considered?

11. Are the benefits worth the harms?
YES

CAN'T TELL

NO

$\mathbf{X}$

$\mathbf{X}$

$\mathbf{X}$

\section{$\mathbf{X}$}

$\mathbf{X}$

$\mathbf{X}$

Not discussed

Not discussed

YES

CAN'T TELL

NO

X

X

X 


\section{Table D-6}

Critical Appraisal Skills Programme (CASP) Randomized Controlled Trials Checklist

Soleimani, A., Heidari, N., Habibi, M. R., Kiabi, F. H., Khademloo, M., Zeydi, A. E., \& Sohrabi, F. B. (2017). Comparing hemodynamic responses to diazepam, propofol and etomidate during anesthesia induction in patients with left ventricular dysfunction undergoing coronary artery bypass graft surgery: A double-blind, randomized clinical trial. Medical Archives, 71(3), 198-203. https://doi.org/10.5455/medarh.2017.71.198-203

\section{A) Are the results of the trial valid?}

1. Did the trial address a clearly focused issue?

2. Was the assignment of patients to treatments randomized?

3. Were all of the patients who entered the trial properly accounted for at its conclusion?

4. Were patients, health workers, and study personnel "blind" to treatment?

5. Were the groups similar at the start of the trial?

6. Aside from the experimental intervention, were groups treated equally?

B) What are the results?

7. How large was the treatment effect?

8. How precise was the estimate of the treatment effect?

C) Will the results help locally?

9. Can the results be applied in your context? (or to the local population?)

10. Were all clinically important outcomes considered?

11. Are the benefits worth the harms?
YES

CAN'T TELL

NO

$\mathbf{X}$

$\mathbf{X}$

$\mathbf{X}$

$\mathbf{X}$

$\mathbf{X}$

$\mathbf{X}$

Not discussed

Not discussed

YES

CAN'T TELL

NO

X

X

$\mathbf{X}$ 


\section{Table D-7}

Critical Appraisal Skills Programme (CASP) Randomized Controlled Trials Checklist

Mala, R., \& Narmada, S. (2017). Prospective randomised study comparing the Haemodynamic and endocrine response to induction with etomidate and propofol in patients undergoing cardiac surgery on cardiopulmonary bypass. Indian Journal of Applied Research, 7(10), 145-146. Retrieved from https://www.worldwidejournals.com/indian-journal-of-applied-research (IJAR)/fileview/October_2017_1506777489_54.pdf

\section{A) Are the results of the trial valid?}

1. Did the trial address a clearly focused issue?

2. Was the assignment of patients to treatments randomized?

3. Were all of the patients who entered the trial properly accounted for at its conclusion?

4. Were patients, health workers, and study personnel "blind" to treatment?

5. Were the groups similar at the start of the trial?

6. Aside from the experimental intervention, were groups treated equally?

B) What are the results?

7. How large was the treatment effect?

8. How precise was the estimate of the treatment effect?

C) Will the results help locally?

9. Can the results be applied in your context? (or to the local population?)

10. Were all clinically important outcomes considered?

11. Are the benefits worth the harms?
YES

CAN'T TELL

NO

$\mathrm{X}$

$\mathrm{X}$

X

X

X

X

Not discussed

Not discussed

YES CAN'T TELL

NO

$\mathrm{X}$

$\mathrm{X}$

$\mathrm{X}$ 


\section{Table D-8}

Critical Appraisal Skills Programme (CASP) Randomized Controlled Trials Checklist

Meena, R., Sharma, R. S., Ranawat, P., Saiyed, A., \& Verma, I. (2017). Comparison of hemodynamic and serum cortisol levels in response to anesthetic induction with etomidate or propofol in patients undergoing CABG surgery. Indian Journal of Clinical Anaesthesia, 4(3), 345-351. https://doi.org/10.18231/2394-4994.2017.0071

A) Are the results of the trial valid?

1. Did the trial address a clearly focused issue?

2. Was the assignment of patients to treatments randomized?

3. Were all of the patients who entered the trial properly accounted for at its conclusion?

4. Were patients, health workers, and study personnel "blind" to treatment?

5. Were the groups similar at the start of the trial?

6. Aside from the experimental intervention, were groups treated equally?

B) What are the results?

7. How large was the treatment effect?

8. How precise was the estimate of the treatment effect?

C) Will the results help locally?

9. Can the results be applied in your context? (or to the local population?)

10. Were all clinically important outcomes considered?

11. Are the benefits worth the harms?
YES

$\mathbf{X}$

$\mathbf{X}$

$\mathbf{X}$

CAN'T TELL

NO

\section{$\mathbf{X}$}

$\mathbf{X}$

$\mathbf{X}$

Not discussed

Not discussed

YES CAN'T TELL NO

$\mathrm{X}$

$\mathrm{X}$

$\mathrm{X}$ 


\section{Table D-9}

Critical Appraisal Skills Programme (CASP) Randomized Controlled Trials Checklist

Hannam, J. A., Mitchell, S. J., Cumin, D., Frampton, C., Merry, A. F., Moore, M. R., \& Kruger, C. J. (2019). Haemodynamic profiles of etomidate vs propofol for induction of anaesthesia: A randomised controlled trial in patients undergoing cardiac surgery. British Journal of Anaesthesia, 122(2), 198-205. https://doi.org/10.1016/j.bja.2018.09.027

\section{A) Are the results of the trial valid?}

1. Did the trial address a clearly focused issue?

2. Was the assignment of patients to treatments randomized?

3. Were all of the patients who entered the trial properly accounted for at its conclusion?

4. Were patients, health workers, and study personnel "blind" to treatment?

5. Were the groups similar at the start of the trial?

6. Aside from the experimental intervention, were groups treated equally?

B) What are the results?

7. How large was the treatment effect?

8. How precise was the estimate of the treatment effect?

C) Will the results help locally?

9. Can the results be applied in your context? (or to the local population?)

10. Were all clinically important outcomes considered?

11. Are the benefits worth the harms?
YES

CAN'T TELL

NO

$\mathbf{X}$

$\mathbf{X}$

$\mathbf{X}$

X

X

$\mathbf{X}$

Not discussed

Not discussed

YES

CAN'T TELL

NO

$\mathbf{X}$

$\mathbf{X}$

$\mathbf{X}$

Note: This study was performed in two phases. The patient was blinded during both phases. Phase I was open-label for the anesthesia provider. In phase II, the anesthesia provider was blinded to the treatment. 


\section{Appendix E}

\section{Cross-Study Analysis}

\begin{tabular}{|c|c|c|}
\hline AUTHOR / YEAR & MEDICATION PROTOCOL & RESULTS \\
\hline $\begin{array}{l}\text { Study } 1 \\
\text { (Basagan-Mogol et al., } \\
\text { 2010) }\end{array}$ & $\begin{array}{l}\text { Group K: ketamine } 2.0 \mathrm{mg} / \mathrm{kg} \\
\text { Group P: propofol } 0.5 \mathrm{mg} / \mathrm{kg}\end{array}$ & Decreased MAP and SVR in group P one minute after induction \\
\hline $\begin{array}{l}\text { Study } 2 \\
\text { (Pandey et al., 2012) }\end{array}$ & $\begin{array}{l}\text { Group E: etomidate } 0.2 \mathrm{mg} / \mathrm{kg} \\
\text { Group p: propofol } 2.0 \mathrm{mg} / \mathrm{kg}\end{array}$ & $\begin{array}{l}\text { Decreased SBP, DBP, SVR, SVRI in group P five minutes after } \\
\text { intubation } \\
\text { More stable hemodynamics group E } \\
\text { Decreased cortisol levels in group E at weaning from CPB } \\
\text { Increased cortisol levels in group P at weaning from CPB }\end{array}$ \\
\hline $\begin{array}{l}\text { Study } 3 \\
\text { (Kaushal et al., 2015) }\end{array}$ & $\begin{array}{l}\text { Group I: propofol } 2.0 \mathrm{mg} / \mathrm{kg} \\
\text { Group II: etomidate } 0.2 \mathrm{mg} / \mathrm{kg}\end{array}$ & $\begin{array}{l}\text { Decreased SBP, DBP, MAP in group I } \\
\text { Decreased SVR in both groups five minutes post induction } \\
\text { Decreased cortisol level group II during/post CPB } \\
\text { Increased cortisol level group I during/post CPB }\end{array}$ \\
\hline $\begin{array}{l}\text { Study } 4 \\
\text { (Shivanna et al., 2015) }\end{array}$ & $\begin{array}{l}\text { Group P: propofol } 0.5 \\
\mathrm{mg} / \mathrm{kg} / \mathrm{min} \\
\text { Group E: etomidate } 0.05 \\
\mathrm{mg} / \mathrm{kg} / \mathrm{min}\end{array}$ & Decreased SBP, MAP, CO and CI in group P after induction \\
\hline
\end{tabular}




\begin{tabular}{|c|c|c|}
\hline $\begin{array}{l}\text { Study } 5 \\
\text { (Kamath et al., 2016) }\end{array}$ & $\begin{array}{l}\text { Group A: propofol } 1.5 \mathrm{mg} / \mathrm{kg} \\
\text { Group B: etomidate } 0.2 \mathrm{mg} / \mathrm{kg}\end{array}$ & $\begin{array}{l}\text { Decreased SBP, MAP, CO and CI in group A after induction } \\
\text { Increased DBP, CO, CI in group A after intubation } \\
\text { Increased MAP, CVP, PCWP in group A five minutes after } \\
\text { intubation }\end{array}$ \\
\hline $\begin{array}{l}\text { Study } 6 \\
\text { (Soleimani et al., 2017) }\end{array}$ & $\begin{array}{l}\text { Group A: propofol } 1.5 \mathrm{mg} / \mathrm{kg} \\
\text { Group B: etomidate } 0.2 \mathrm{mg} / \mathrm{kg} \\
\text { Group C: diazepam } 0.3 \mathrm{mg} / \mathrm{kg}\end{array}$ & $\begin{array}{l}\text { Decreased SBP, DBP, MAP in all groups one minute after } \\
\text { induction, remaining low longer in group A } \\
\text { Larger number of patients in group A required rescue ephedrine } \\
\text { administration }\end{array}$ \\
\hline $\begin{array}{l}\text { Study } 7 \\
\text { (Mala \& Narmala, 2017) }\end{array}$ & $\begin{array}{l}\text { Propofol group: propofol } 2.0 \\
\mathrm{mg} / \mathrm{kg} \\
\text { Etomidate group: etomidate } 0.2 \\
\mathrm{mg} / \mathrm{kg}\end{array}$ & $\begin{array}{l}\text { Decrease in SBP in propofol group after induction, much lower } \\
\text { five minutes after induction } \\
\text { Decrease in CI two minutes and three minutes after induction in } \\
\text { propofol group } \\
50 \% \text { reduction in cortisol in etomidate group, nearly twofold } \\
\text { increase in cortisol in propofol group }\end{array}$ \\
\hline $\begin{array}{l}\text { Study } 8 \\
\text { (Meena et al., 2017) }\end{array}$ & $\begin{array}{l}\text { Group A: etomidate } 0.3 \mathrm{mg} / \mathrm{kg} \\
\text { Group B: propofol } 2.0 \mathrm{mg} / \mathrm{kg}\end{array}$ & $\begin{array}{l}\text { Decreased cortisol group A, increased cortisol group B } \\
\text { Decreased SBP, DBP, SVR, SVRI after induction group B } \\
\text { Increased HR, SBP after intubation group A }\end{array}$ \\
\hline $\begin{array}{l}\text { Study } 9 \\
\text { (Hannam et al., 2019) }\end{array}$ & $\begin{array}{l}\text { Propofol group: propofol titrated } \\
\text { at anesthetist's discretion to } \\
\text { achieve loss of response to } \\
\text { verbal command } \\
\text { Etomidate group: etomidate } \\
\text { titrated at anesthetist's discretion }\end{array}$ & $34 \%$ greater reduction in MAP with propofol \\
\hline
\end{tabular}




\begin{tabular}{|l|l|l|}
\hline & $\begin{array}{l}\text { to achieve loss of response to } \\
\text { verbal command }\end{array}$ & \\
\hline
\end{tabular}

